\title{
Dementia wellbeing and COVID19: Review and expert consensus on current research and knowledge gaps
}

\author{
Liu, KY
}

http://hdl.handle.net/10026.1/17862

\author{
10.1002/gps.5567 \\ International Journal of Geriatric Psychiatry \\ Wiley
}

All content in PEARL is protected by copyright law. Author manuscripts are made available in accordance with publisher policies. Please cite only the published version using the details provided on the item record or document. In the absence of an open licence (e.g. Creative Commons), permissions for further reuse of content should be sought from the publisher or author. 


\title{
Dementia wellbeing and COVID-19: Review and expert consensus on current research and knowledge gaps
}

\author{
Kathy Y. Liu ${ }^{1}$ (1) | Robert Howard ${ }^{1}$ | Sube Banerjee ${ }^{2}$ | Adelina Comas-Herrera ${ }^{3}$ | \\ Joanne Goddard $^{4}$ | Martin Knapp ${ }^{3}$ | Gill Livingston ${ }^{1}$ | Jill Manthorpe ${ }^{5}$ | \\ John T. O'Brien ${ }^{6}$ | Ross W. Paterson ${ }^{7}$ | Louise Robinson ${ }^{8}$ ( | Martin Rossor ${ }^{7}$ | \\ James B. Rowe ${ }^{9,10}$ | David J. Sharp ${ }^{11,12}$ | Andrew Sommerlad ${ }^{1}$ | \\ Aida Suárez-González ${ }^{7}$ | Alistair Burns ${ }^{13}$ ๑ \\ ${ }^{1}$ Division of Psychiatry, University College London, London, UK \\ ${ }^{2}$ Faculty of Health, University of Plymouth, Plymouth, UK \\ ${ }^{3}$ Department of Health Policy, London School of Economics and Political Science, Care Policy and Evaluation Centre, London, UK \\ ${ }^{4}$ Economic and Social Research Council, UK Research and Innovation, Swindon, UK \\ ${ }^{5}$ NIHR Policy Research Unit in Health and Social Care Workforce, King's College London, London, UK \\ ${ }^{6}$ Department of Psychiatry, University of Cambridge School of Clinical Medicine, Cambridge, UK \\ ${ }^{7}$ Dementia Research Centre, Queen Square UCL Institute of Neurology, University College London, London, UK \\ ${ }^{8}$ Population Health Sciences Institute, Faculty of Medical Sciences, Newcastle University, Newcastle, UK \\ ${ }^{9}$ Medical Research Council Cognition and Brain Sciences Unit, University of Cambridge, Cambridge, UK \\ ${ }^{10}$ Department of Clinical Neurosciences, University of Cambridge, Cambridge, UK \\ ${ }^{11}$ Department of Brain Sciences, Imperial College London, London, UK \\ ${ }^{12}$ UK Dementia Research Institute, Care Research and Technology Centre, Imperial College London, London, UK \\ ${ }^{13}$ Division of Neuroscience and Experimental Psychology, The University of Manchester, Manchester, UK
}

\section{Correspondence}

Kathy Y. Liu, Division of Psychiatry, Maple House, 149 Tottenham Court Road, London W1T 7NF, UK.

Email: kathy.liu@ucl.ac.uk

\section{Funding information}

Medical Research Council, Grant/Award Number: MR/S021418/1; UK Dementia Research Institute; UK Research and Innovation; University of Worcester; University College London Hospitals NHS Foundation Trust; NIHR Biomedical Research Centre, Royal Marsden NHS Foundation Trust/Institute of Cancer Research; Economic and Social Research Council; Engineering and Physical Sciences Research Council

\begin{abstract}
Objectives: In response to a commissioned research update on dementia during the COVID-19 pandemic, a UK-based working group, comprising dementia researchers from a range of fields and disciplines, aimed to describe the impact of the pandemic on dementia wellbeing and identify priorities for future research.

Methods: We supplemented a rapid literature search (including unpublished, nonpeer reviewed and ongoing studies/reports) on dementia wellbeing in the context of COVID-19 with expert group members' consensus about future research needs. From this we generated potential research questions the group judged to be relevant that were not covered by the existing literature.

Results: Themes emerged from 141 studies within the six domains of the NHS England COVID-19 Dementia Wellbeing Pathway: Preventing Well, Diagnosing Well, Treating Well, Supporting Well, Living Well and Dying Well. We describe
\end{abstract}

This is an open access article under the terms of the Creative Commons Attribution License, which permits use, distribution and reproduction in any medium, provided the original work is properly cited.

(c) 2021 The Authors. International Journal of Geriatric Psychiatry published by John Wiley \& Sons Ltd. 
current research findings and knowledge gaps relating to the impact on people affected by dementia (individuals with a diagnosis, their carers and social contacts, health and social care practitioners and volunteers), services, research activities and organisations. Broad themes included the potential benefits and risks of new models of working including remote healthcare, the need for population-representative longitudinal studies to monitor longer-term impacts, and the importance of reporting dementia-related findings within broader health and care studies.

Conclusions: The COVID-19 pandemic has had a disproportionately negative impact on people affected by dementia. Researchers and funding organisations have responded rapidly to try to understand the impacts. Future research should highlight and resolve outstanding questions to develop evidence-based measures to improve the quality of life of people affected by dementia.

KEYWORDS

COVID-19, dementia, research, wellbeing

\section{Key Points}

- The COVID-19 pandemic has had a disproportionately negative impact on people affected by dementia, dementia services and research.

- Further research on the impacts of the pandemic is needed, and directions for future work are identified in this study.

- It is important to explore the potential benefits and risks of remote health and care, design inclusive and longitudinal studies to monitor longer-term impacts, and report dementiaspecific findings within broader studies.

\section{1 | INTRODUCTION}

The COVID-19 coronavirus pandemic disproportionately affects people living with dementia who have a substantially increased risk of infection and subsequent death, ${ }^{1,2}$ accounting for $31 \%$ of all COVID-19 related deaths. ${ }^{3}$ People living with dementia are also at risk of and affected by the social isolation and reduced access to health and social care that accompany pandemic restrictions. In the UK, people affected by dementia (individuals with dementia, their carers and social contacts, health and social care practitioners and volunteers), were 'worst hit' by the pandemic. ${ }^{4,5}$ Dementia services, research activities and funding have been reduced, while health inequalities have widened. ${ }^{6}$ Initiatives to investigate and address these impacts have begun to identify learning from pandemic experiences, but research that includes people living with dementia has been affected because of their vulnerability to COVID-19.

For those working to support people living with dementia and carers, it is important to understand findings from existing research on COVID-19 and dementia, and how to make the best use of that research to inform policy and practice and identify key research gaps to direct future work. In response to the impact of the pandemic on dementia wellbeing, NHS England published a guide to delivering policy aspirations in the context of COVID-19, based on the NHS England Dementia Well Pathway for delivering best dementia care ${ }^{7}$. This pathway provides a framework of care and support that people with dementia, and their carers, need at each stage of their journey, from prevention to end-of-life, ${ }^{8}$ so that dementia care, research and awareness can be optimised. ${ }^{9}$ The guide to dementia wellbeing in the COVID-19 pandemic ${ }^{7}$ highlighted priorities and actions and provided guidance and resources within six phases of dementia wellbeing: Preventing Well, Diagnosing Well, Treating Well, Supporting Well, Living Well and Dying Well. The English Department of Health and Social Care (DHSC) Dementia Programme Board subsequently commissioned a research update on dementia during the COVID-19 pandemic.

This paper comes from a literature search for studies about dementia and COVID-19 and the expert consensus of a working group formed in response to the question from the Dementia Programme Board in November 2020. Using the COVID-19 Dementia Wellbeing Pathway ${ }^{7}$ as a framework, we aim to describe completed and ongoing research on dementia wellbeing and COVID-19 and identify key directions for future work.

\section{2 | METHODS}

Relevant questions, research databases and completed and ongoing studies were identified by members of the working group during an initial meeting and subsequent correspondence. Expertise of the UKbased working group included researchers from health, economic and 
social care who work on dementia-related topics (see Table S1 for further details of the working group). Initial discussions were supplemented by a literature search to identify published and unpublished research on COVID-19 and dementia at the end of 2020. We identified areas of consensus on the important gaps in the literature and future directions for research. We report findings aligned with the six steps of the COVID-19 Dementia Wellbeing Pathway and specifically mention the UK studies.

\section{1 | Literature search and study selection}

One author $(\mathrm{KL})$ led the literature search, reviewed titles and abstracts for relevance and then extracted data from relevant full texts. Databases were searched using specific search terms (Table 1 ) on 9th December 2020, which was updated on 7th January 2021 in consultation with members of the expert group.

Included studies were research articles in the English language from any country on COVID-19 and dementia or mild cognitive impairment in individuals of any age. Individuals with mild cognitive impairment are often assessed and/or followed up by memory services, and a significant proportion are experiencing the early stages of a neurodegenerative illness and will progress to dementia. We included primary studies and reviews, as well as case series, commentaries, position papers and policy documents if they reported quantitative or qualitative findings in relation to COVID-19 and dementia wellbeing. We excluded studies that investigated risk for development of dementia secondary to COVID-19, the mechanisms of disease, or the impact of dementia on COVID-19 mortality or infection, without identifying specific risk factors within dementia. Case reports were excluded, as studies of individuals were judged to be insufficiently informative for the purpose of this study, as were articles based purely on data that were not obtained during the COVID-19 pandemic period (before November 2019).

Any additional studies or reports that the expert group judged to be consistent with the aim of identifying the scope of existing research on COVID-19 and dementia wellbeing, but that had not emerged from the literature search, were combined with the search results and reported (Figure 1). For example, some specific studies on people living or working in long-term care facilities, such as care homes, did not explicitly report that participants with dementia were included in the study, but were judged to be relevant as more than $70 \%$ of UK care home residents are estimated to have dementia. ${ }^{14,15}$ Some expert members were also aware of ongoing funded studies that had adjusted their existing project to explore the impact of COVID-19, non-peer reviewed UK survey-based reports from charities, ${ }^{4,5,16,17}$ as well as two reports published by the 'LTCcovid' collaboration (www.Itccovid.org), which was set up to gather resources to support long term care responses to COVID-19. ${ }^{3,18}$ Some members were aware of funded studies that have yet to be announced; we have not included them in the tables but provide some details in the main text.

\section{3 | RESULTS}

The database searches and screening of articles identified 141 relevant studies (see Figure 1, 2 and Tables 2-7). We describe the main findings from these studies and key gaps in research identified by expert consensus in relation to each of the six steps of the COVID-19 Dementia Wellbeing Pathway, summarised in Box 1.

Preventing Well: Keeping fit and active to prevent the mental and physical consequences of isolation (Table 2).

The overall negative impact of COVID-19-related restrictions on people living with dementia and their carers' wellbeing, mental health and functioning was explored by over 30 publications, which included participants with a range of different dementias. ${ }^{129}$ A number of studies included in the Supporting Well and Living Well domains, described below, have the potential to help prevent the negative impact of further waves of the pandemic on dementia wellbeing. Most of the dementia-focused studies used cross-sectional surveys and relied on subjective retrospective ratings, and few compared findings with pre-pandemic outcome data, revealing a need for further quantitative and longitudinal research.

TABLE 1 Databases and search terms used for the literature search

\begin{tabular}{|c|c|c|}
\hline Database type & Database name & Search terms \\
\hline Published studies & Web of Science & \multirow{2}{*}{$\begin{array}{l}\text { '(SARS-CoV-2 OR COVID-19 OR hCoV-19 OR 2019-nCoV) AND } \\
\text { (dementia OR Alzheimer OR neurodegenerative OR "mild } \\
\text { cognitive impairment")' in titles, abstracts and full texts. }\end{array}$} \\
\hline $\begin{array}{l}\text { Registered systematic } \\
\text { reviews }\end{array}$ & PROSPERO & \\
\hline Preprint databases & $\begin{array}{l}\text { BioRxiv and MedRxiv (these did not support parentheses for } \\
\text { the search) }\end{array}$ & 'Covid AND dementia' within titles and abstracts \\
\hline \multirow{3}{*}{$\begin{array}{l}\text { Ongoing UK funded } \\
\text { studies }\end{array}$} & Long Term Care (LTC) Responses to COVID-19 project $^{10}$ & \multirow[t]{2}{*}{ Projects related to 'dementia' } \\
\hline & $\begin{array}{l}\text { COVID-19 UK Research and Innovation (UKRI) grants } \\
\text { databases }{ }^{11}\end{array}$ & \\
\hline & $\begin{array}{l}\text { UK National Institute for Health Research (NIHR) Funding } \\
\text { and Awards database }{ }^{12}\end{array}$ & Projects related to 'dementia' and 'COVID' \\
\hline
\end{tabular}




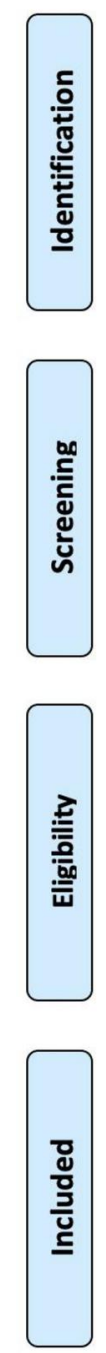

Records identified through database searching $\mathrm{n}=1157$

(PubMed $n=601$, WoS $n=374$, BioRxiv and MedRxiv $=43$, PROSPERO $=36$, LTCcovid $=13$ ongoing, UKRI research $n=82$ and $n=7$ innovation grants, NIHR funding and awards = 1)

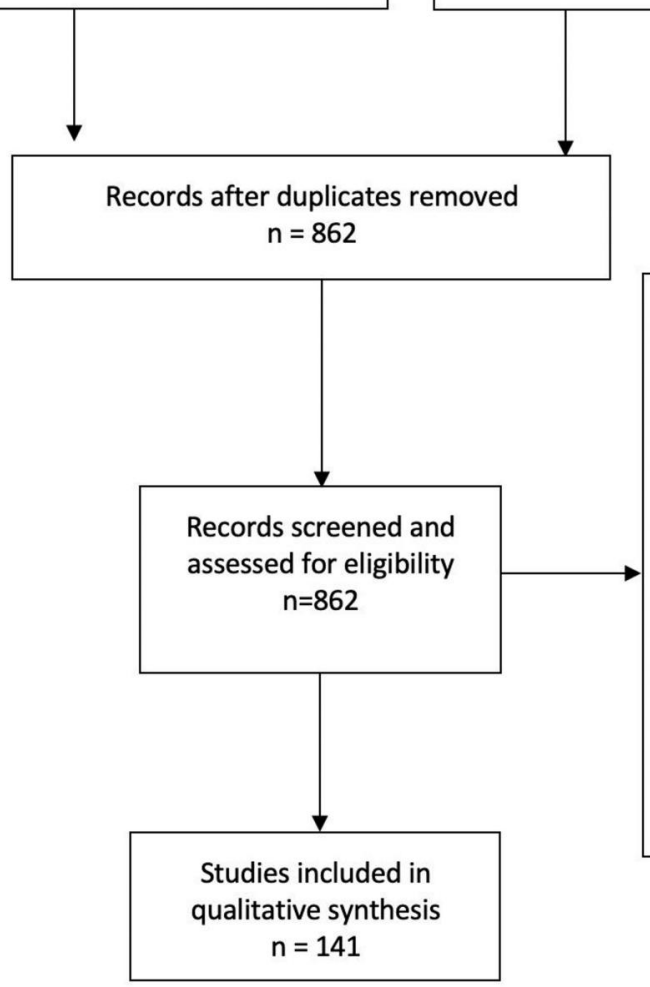

Additional records identified from expert consensus group members

$$
n=17
$$

$3=$ projects with COVID-related adjustments (Brotherhood 2020, PriDem project, Samsi 2021),

2= preprints (Bhome 2020, Lorenz-Dant 2021), 1 = Egunsola 2020 (non-peer reviewed rapid review), $2=$ LTCcovid project reports, 4 = survey-based reports from UK charities (Age UK, Alzheimer's Society, Dementia UK, Carers UK), 2=national reports (NHS England 2020, CQC 2021), $3=$ specific published or ongoing care home studies (Nyashanu 2020, Fitzpatrick 2020, Stall 2020)

FIGURE 1 The number of records identified, included and excluded, and the reasons for exclusions. Adapted from: Moher D, Liberati A, Tetzlaff J, Altman DG, The PRISMA Group (2009) ${ }^{13}$

Most studies were also based on community-dwelling dyads, and more research is needed on the impact of restrictions on the wellbeing of care home residents with dementia, as well as care home staff and other practitioners who work with people living with dementia. Future data on these aspects in the UK may emerge, especially if findings specific to people affected by dementia are analysed and reported within broader studies. A number of such ongoing or completed broader studies in care home residents and staff, the health and social care workforce, and individuals and families were identified by the expert group and are listed in Table 2 and described in more detail in Table S2.
Another theme, related to the prevention of COVID-19 in dementia, was the reduced ability of many people living with dementia to understand and comply with pandemic restrictions, social distancing and the use of face masks, ${ }^{50-53}$ potentially increasing vulnerability to COVID-19 infection. Long-term care facility characteristics, such as size, degree of crowding, low levels of testing and personal protective equipment (PPE) were related to more COVID-19 outbreaks. ${ }^{58-60}$ Available published COVID-19 vaccine trial data indicate that all participants provided written consent (implying preserved mental capacity) and none had dementia. ${ }^{130}$ It will be important to monitor the effects of vaccines in people with dementia, many of whom will likely lack mental 
FIGURE 2 Distribution of COVID-19 and dementia wellbeing research mapped onto the NHS England Dementia Well Pathway. Figures show number of studies (percentage of total)

\section{Distribution of Covid and Dementia Research Mapped onto the NHS England Dementia Well Pathway}

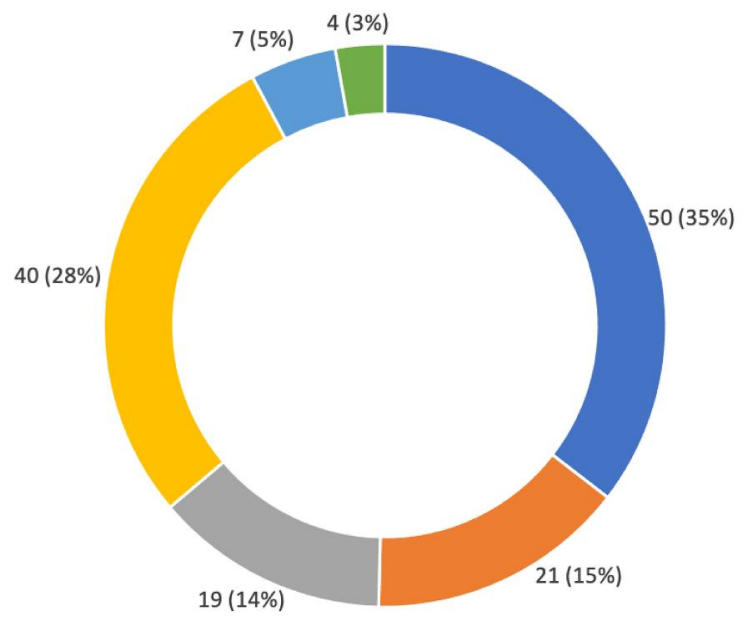

- Preventing Well = Diagnosing Well $=$ Treating Well $=$ Supporting Well $=$ Living Well $\equiv$ Dying Well

capacity to consent to vaccination and usually have multiple physical co-morbidities.

Published studies also explored risk factors for more severe COVID-19 infection in people with dementia, such as APOE4 homozygosity, ${ }^{54}$ institutionalization (residence in long-term care facilities) and physical comorbidities. 9,56,57,64

The consensus group felt that health and socio-economic inequalities were important and under-researched in many dementia studies, and future studies should ensure that research on COVID-19 is inclusive, ${ }^{131}$ encompassing people with a range of socio-demographic characteristics such as ethnicities. The DETERMIND-C19 study (Table 5, Banerjee et al., UKRI) is investigating inequalities and inequities in dementia care and outcomes related to the COVID-19 pandemic. Health inequalities are also present in other countries and vary between countries, which requires further investigation and policy solutions. ${ }^{132}$

Diagnosing Well: Maintaining diagnostic services and awareness of symptoms of COVID-19 ( 3).

Reduced access or referral to diagnostic services and reduced diagnosis rates related to the pandemic were described. ${ }^{4}$ This was despite the reported increased use of telemedicine and in contrast to overall increased mental health secondary care referrals. ${ }^{78}$ In England, the national dementia diagnosis rate has declined steadily since February 2020, dropping to $62.7 \%$ in November, ${ }^{133}$ lower than the national target of $66.7 \%^{134}$ and the previous year $(68.2 \%$ in November 2019). Future research is needed to understand the impact of the loss of face-to-face assessments and access to diagnostic services during the pandemic.

Alternative methods to communicating with people affected by dementia (e.g., via telephone or video calls) have arisen in response to the disruption of normal service provision. ${ }^{76}$ The feasibility of remote assessment and virtual diagnosis of dementia in home-dwelling participants during the COVID pandemic was studied, ${ }^{70,135}$; and members of the group were aware that the UK Dementia Research Institute (DRI) Care Research and Technology Centre (CR\&T) is working on developing digital tools for remote cognitive testing to support memory clinics and a remote technology programme to detect signs of COVID-19 infection in people with dementia at home (Sharp and Barnaghi, UKRI). Studies or reports that reviewed options for remote cognitive assessments or virtual memory clinics during the pandemic ${ }^{72,73,74,75,76}$ cautioned that reliance on technology risks excluding sections of the population, for example, those who cannot use or possess the technology, and could thereby worsen pre-existing inequalities.

Eight studies reported that presentation of COVID-19 in dementia is often asymptomatic or atypical and may include hypoactive delirium, making it more difficult to detect without accurate polymerase chain reaction (PCR) tests, especially as self-reporting of symptoms can also be unreliable (Table 3). Despite this vulnerability among people living with dementia, a London-based study showed that testing was only available at a later stage in older adults' psychiatric wards versus general hospitals at the start of the pandemic during the first UK lockdown, which was associated with outbreaks. ${ }^{67}$ A London-based study of four nursing homes, where most residents (57\%) had dementia, reported that $40 \%$ of COVID test-positive residents were asymptomatic and there was a mortality rate of $26 \%,{ }^{68}$ highlighting the need to prioritise nursing home testing and rapid infection control measures in this setting. Replication of studies conducted during the start of the pandemic at later periods, for example, subsequent lockdowns, would establish whether infection control improved and if high rates of SARS-CoV-2 antibody seropositivity ${ }^{68}$ had any impact on infection and mortality rates.

No studies had yet investigated the prevalence of post-COVID syndrome, or 'Long COVID'136,137 in people with dementia, which 


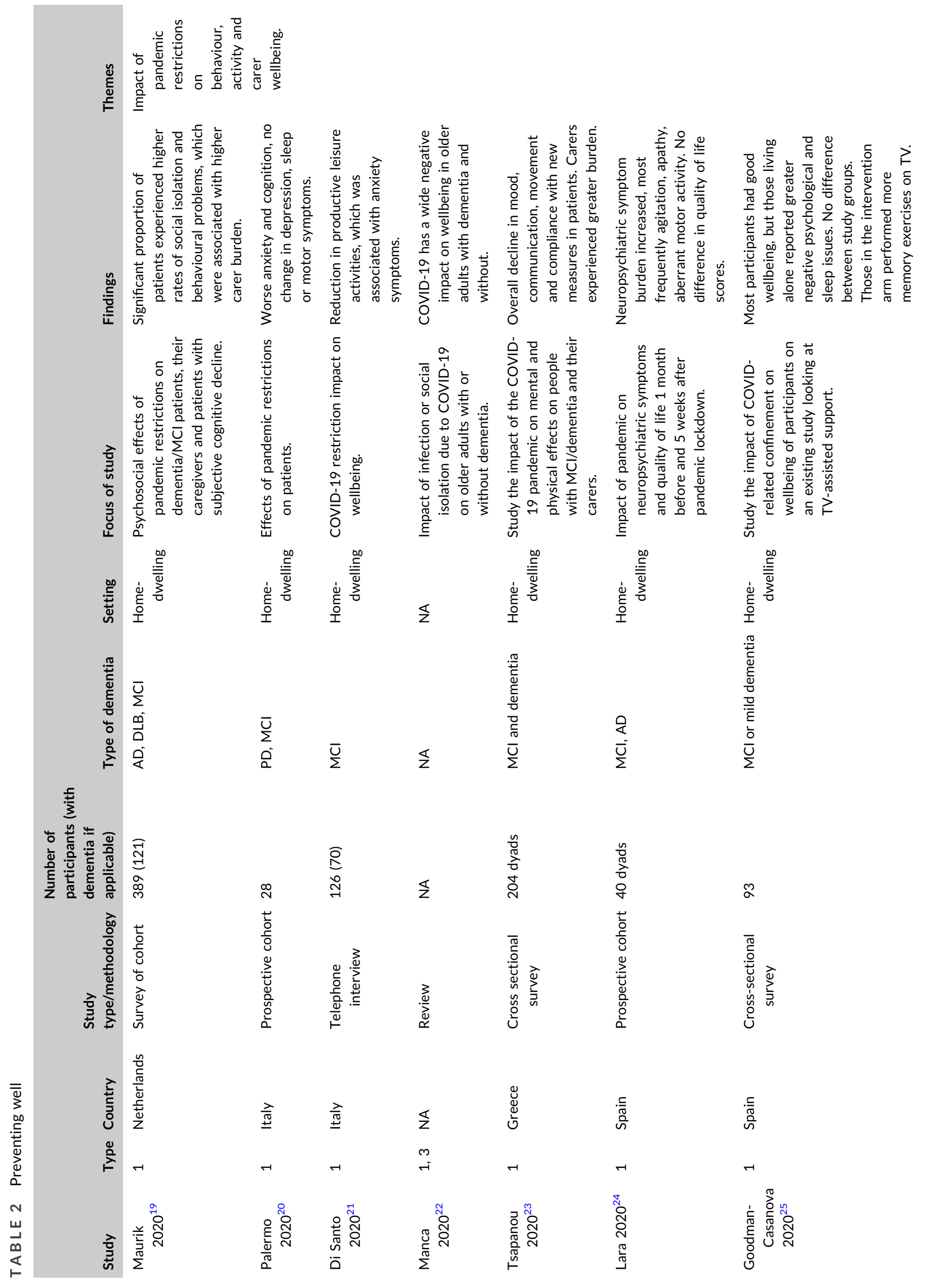




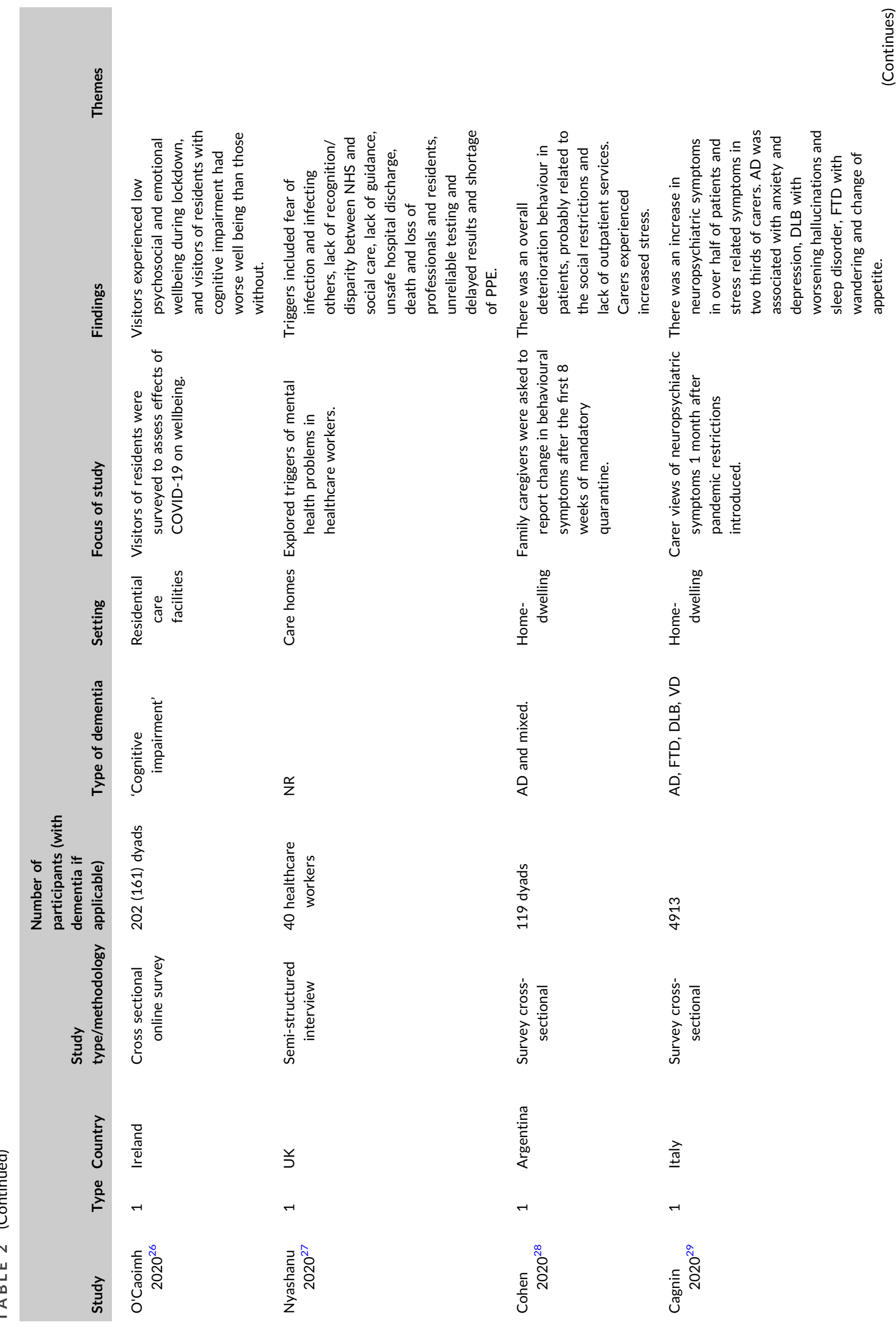




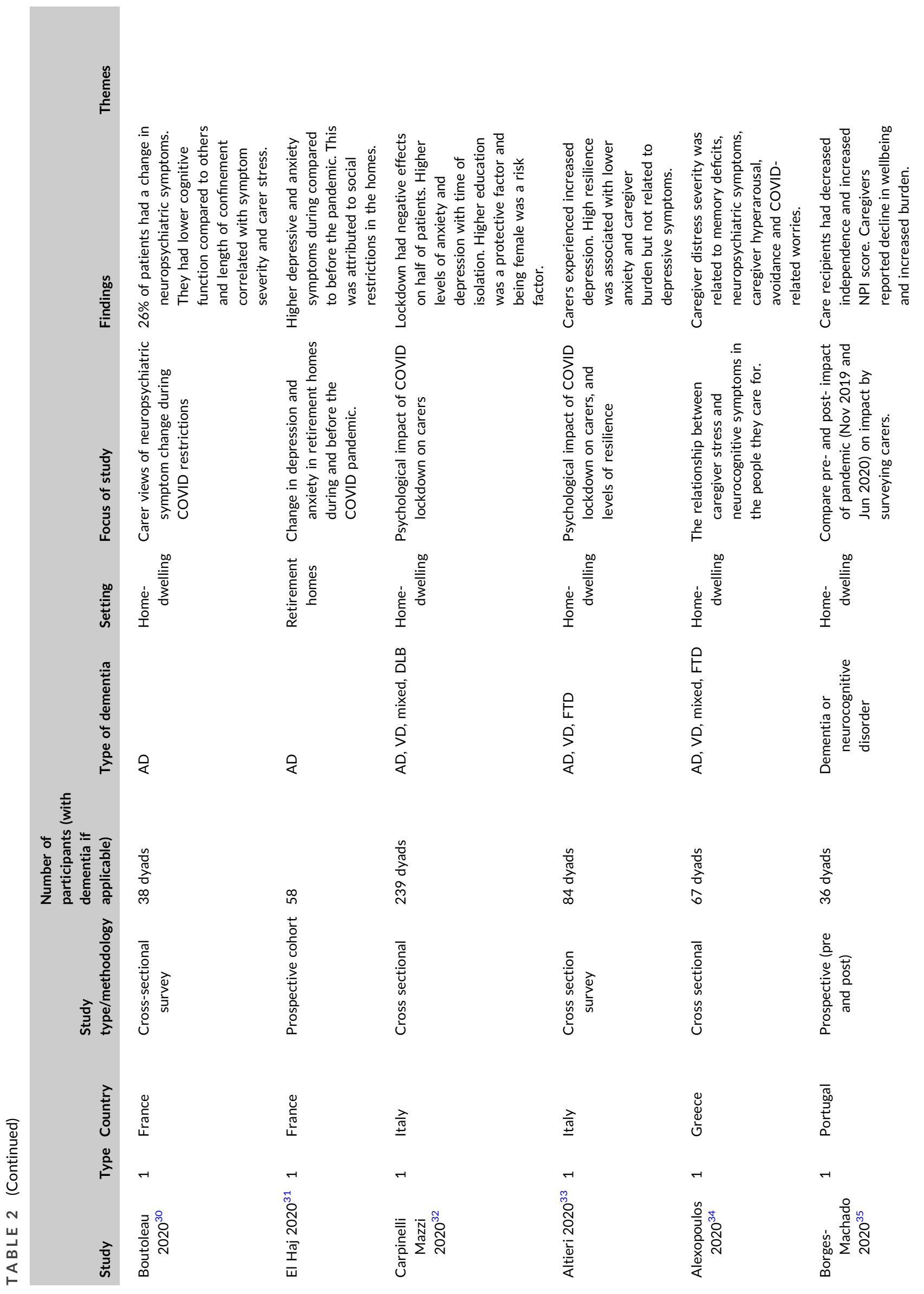



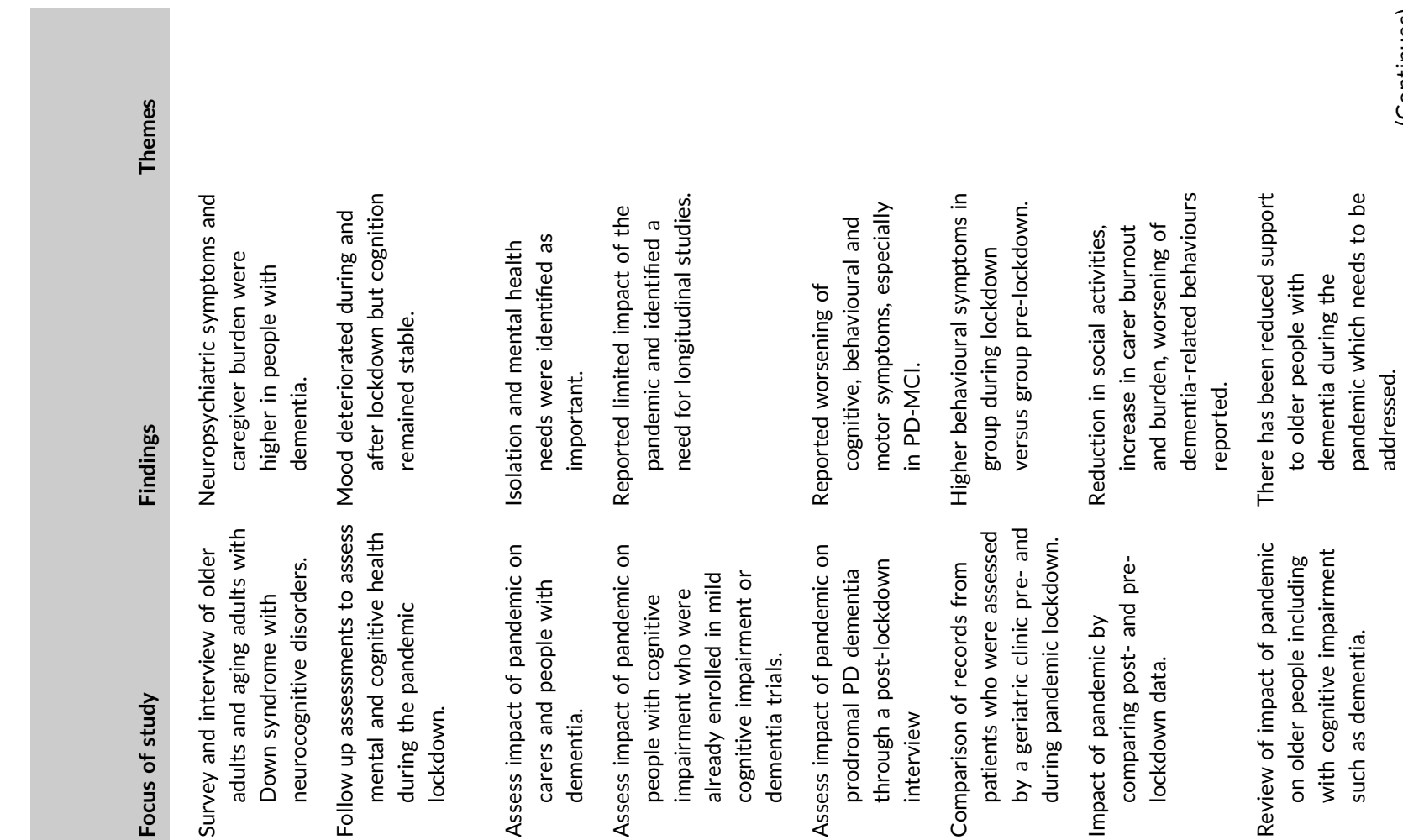

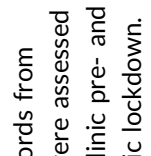
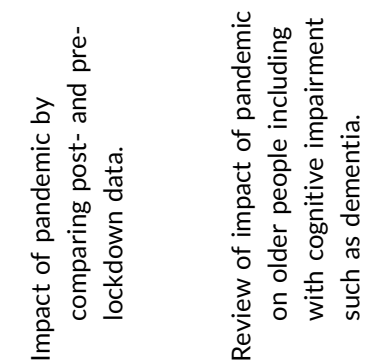

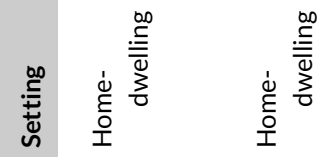

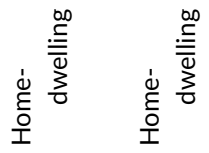

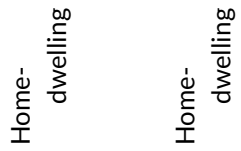

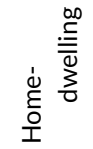

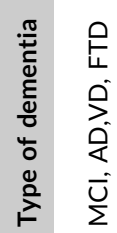

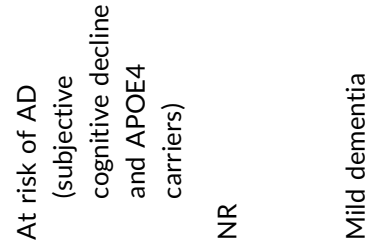

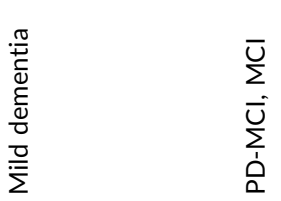

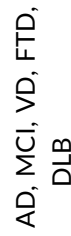

$\frac{\alpha}{z}$

亦

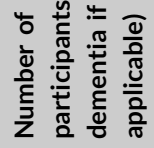

\begin{tabular}{l}
1 \\
\hline \\
8 \\
\hline
\end{tabular}

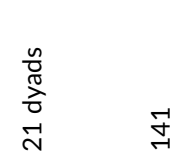

$\frac{n}{0}$
$\frac{0}{2}$
$\frac{\pi}{0}$
$\frac{0}{0}$

$\frac{n}{0}$
$\frac{0}{0}$
0
0

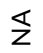

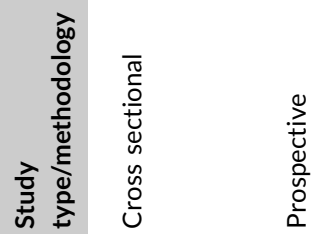

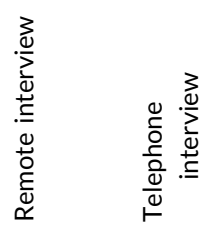

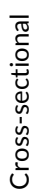

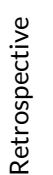

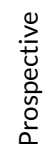

$\frac{3}{\stackrel{u}{u}}$

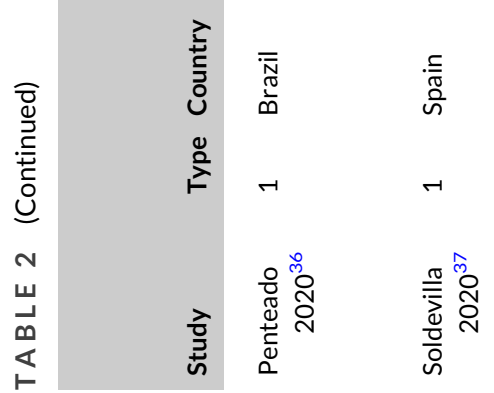

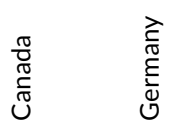

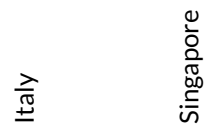

$\frac{5}{\pi}$
के

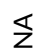




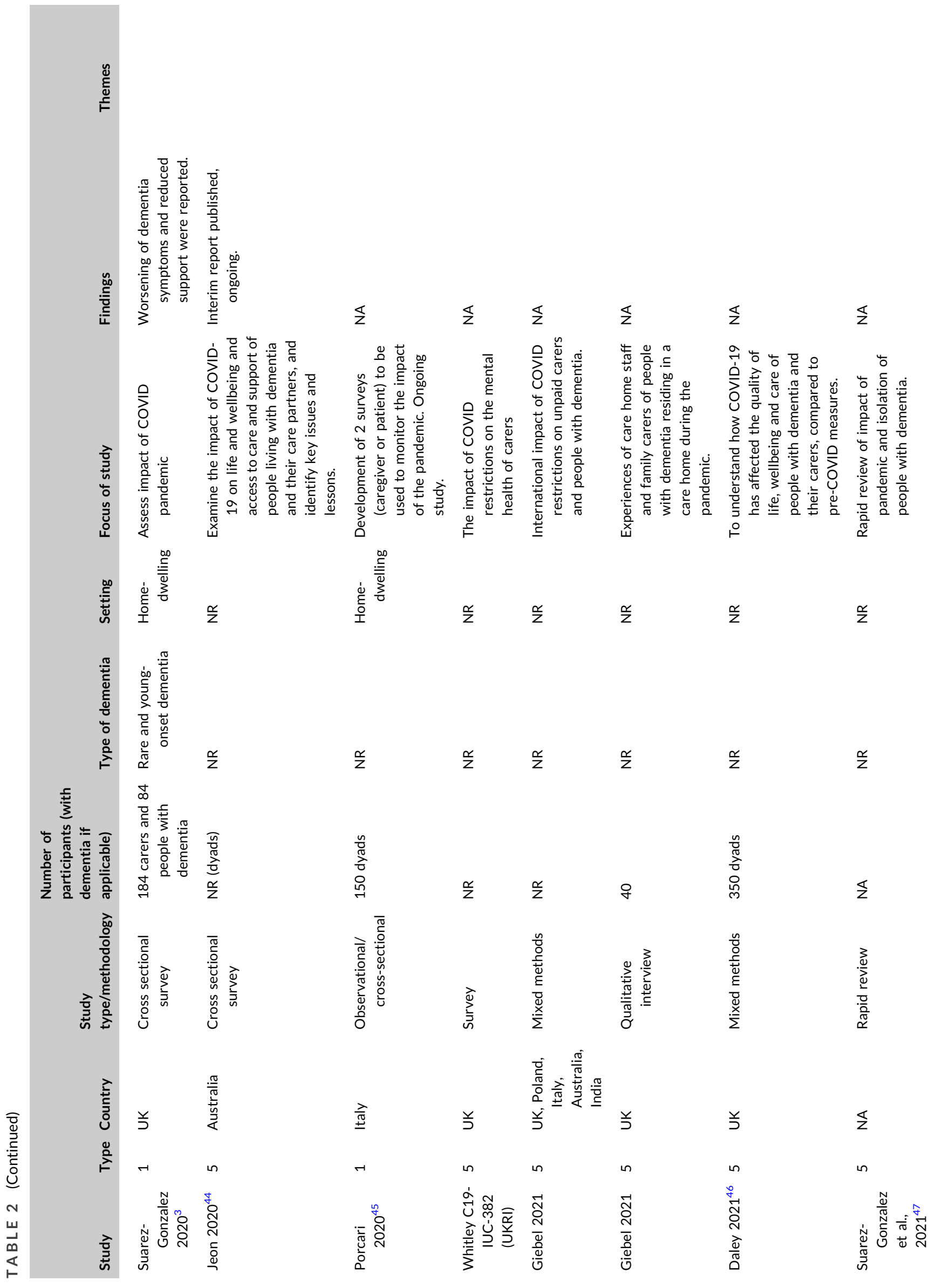




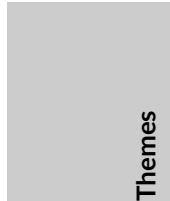

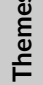

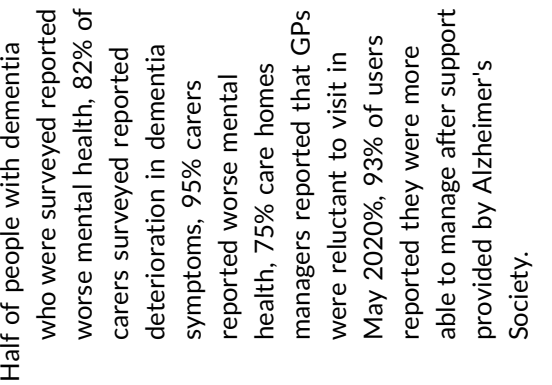

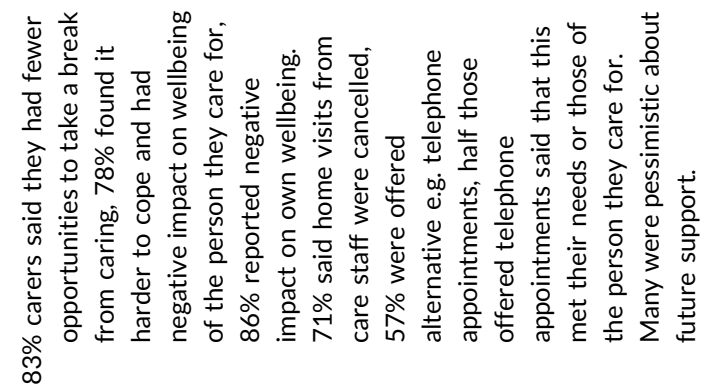



$\varangle \quad \frac{\frac{4}{\pi}}{1}$
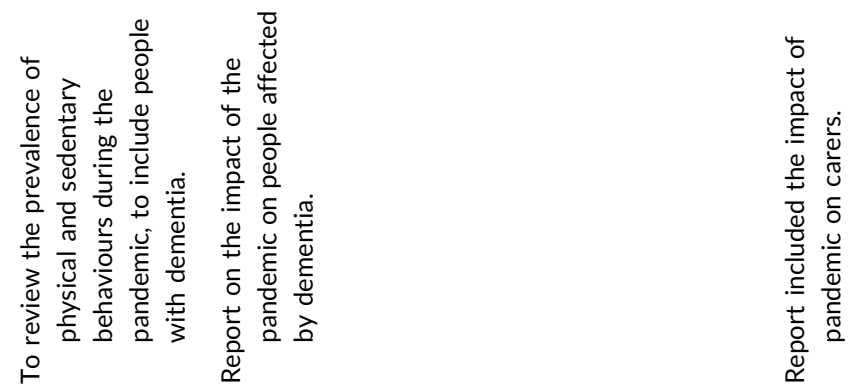

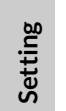

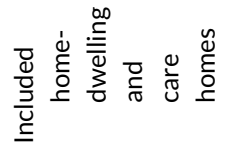

$\stackrel{\alpha}{z}$

兴

$\frac{\mathscr{N}}{z}$

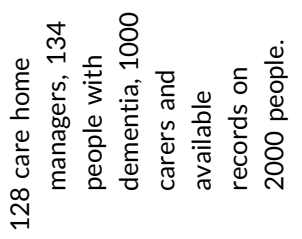

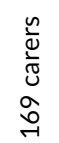

를

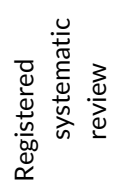

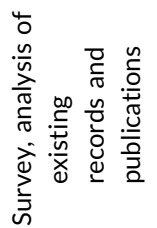

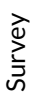

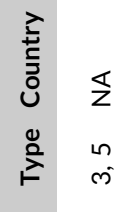

כ๋

弚

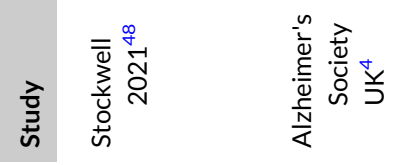

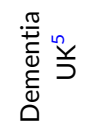




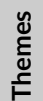
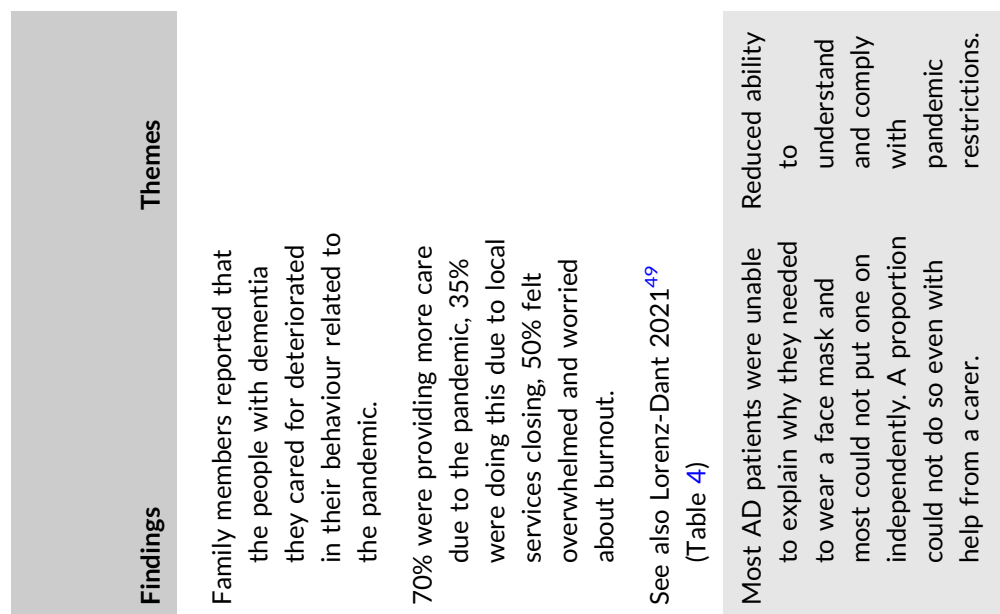

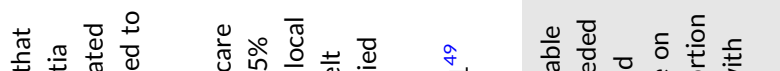

बै

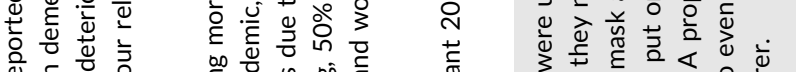

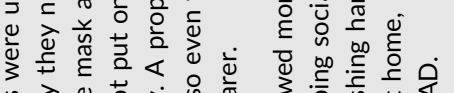

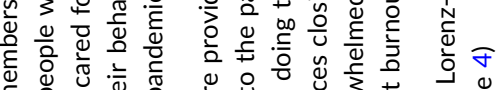

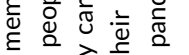

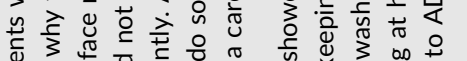

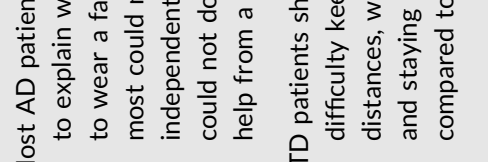
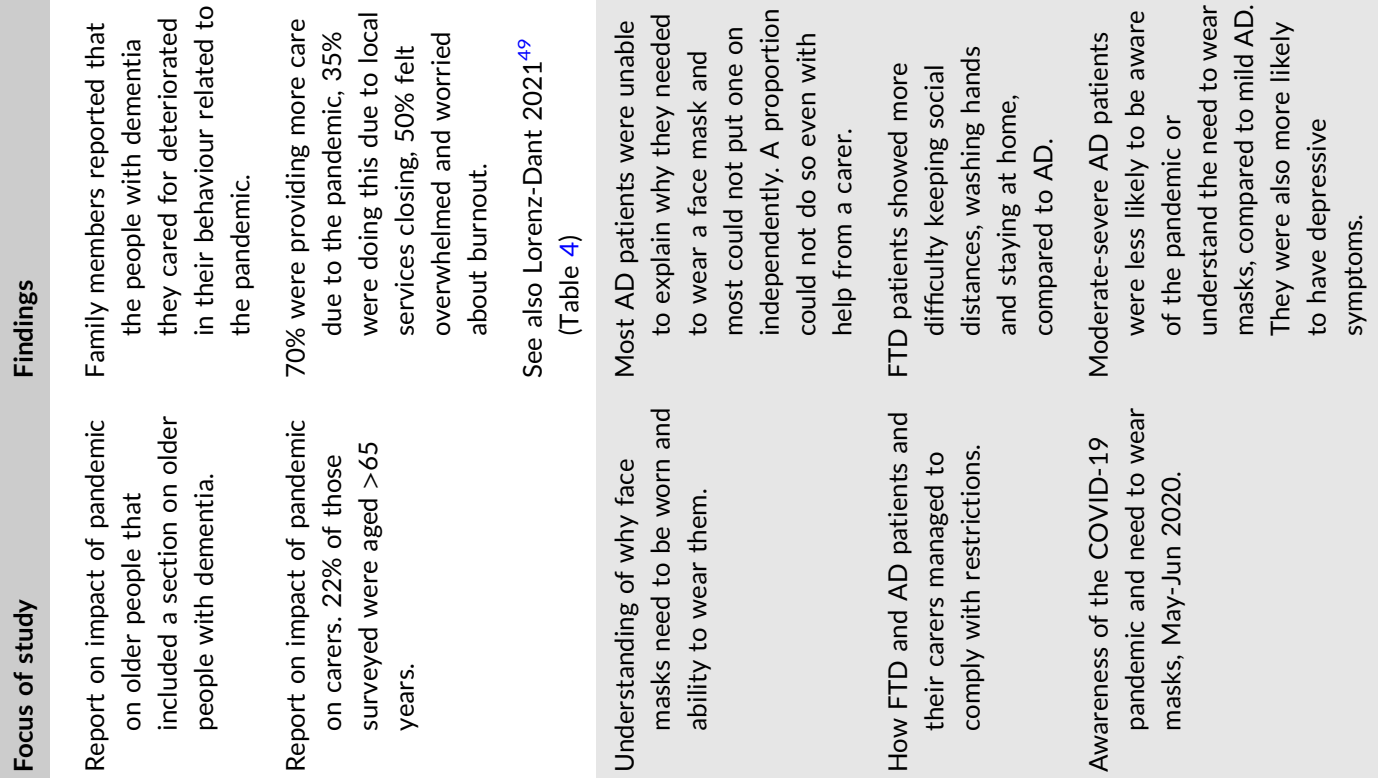

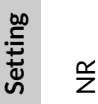
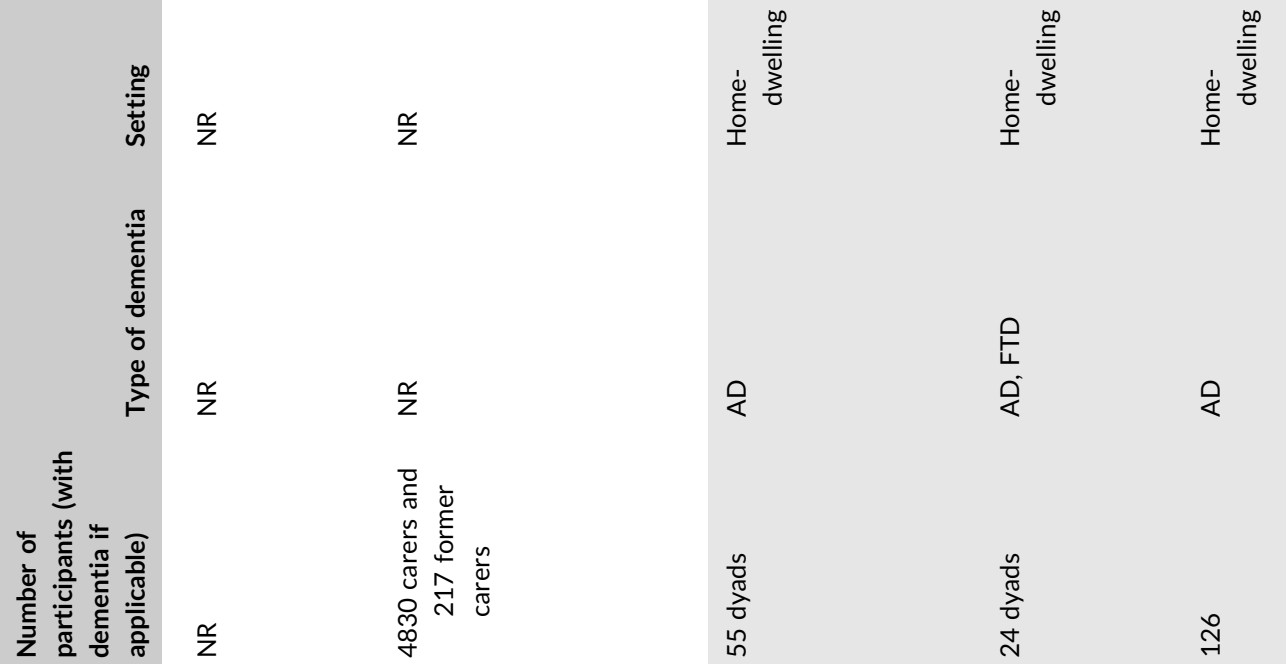

$\frac{\mathscr{c}}{z}$

\&

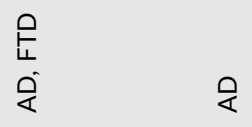

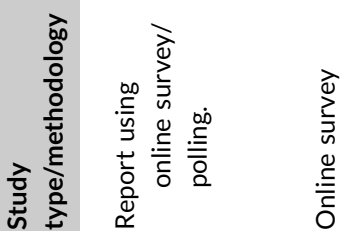

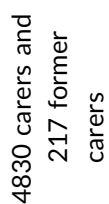

岂
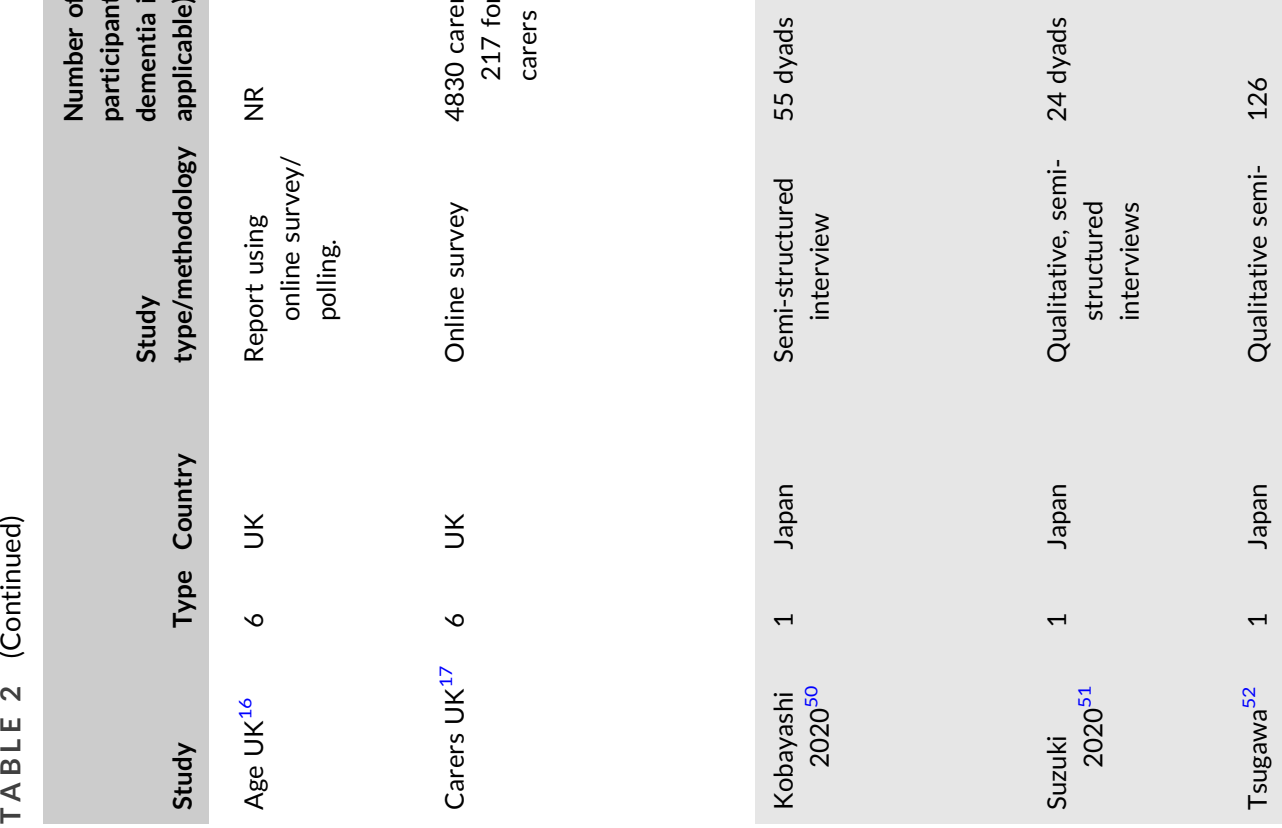

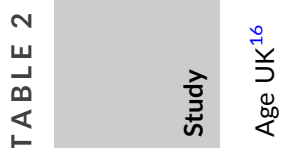

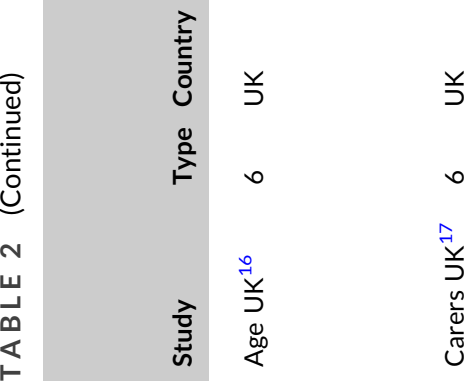

כ

든
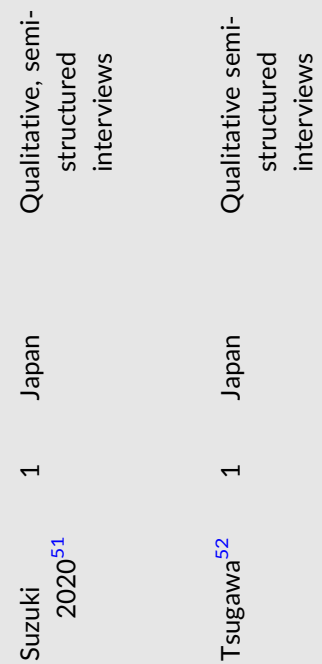


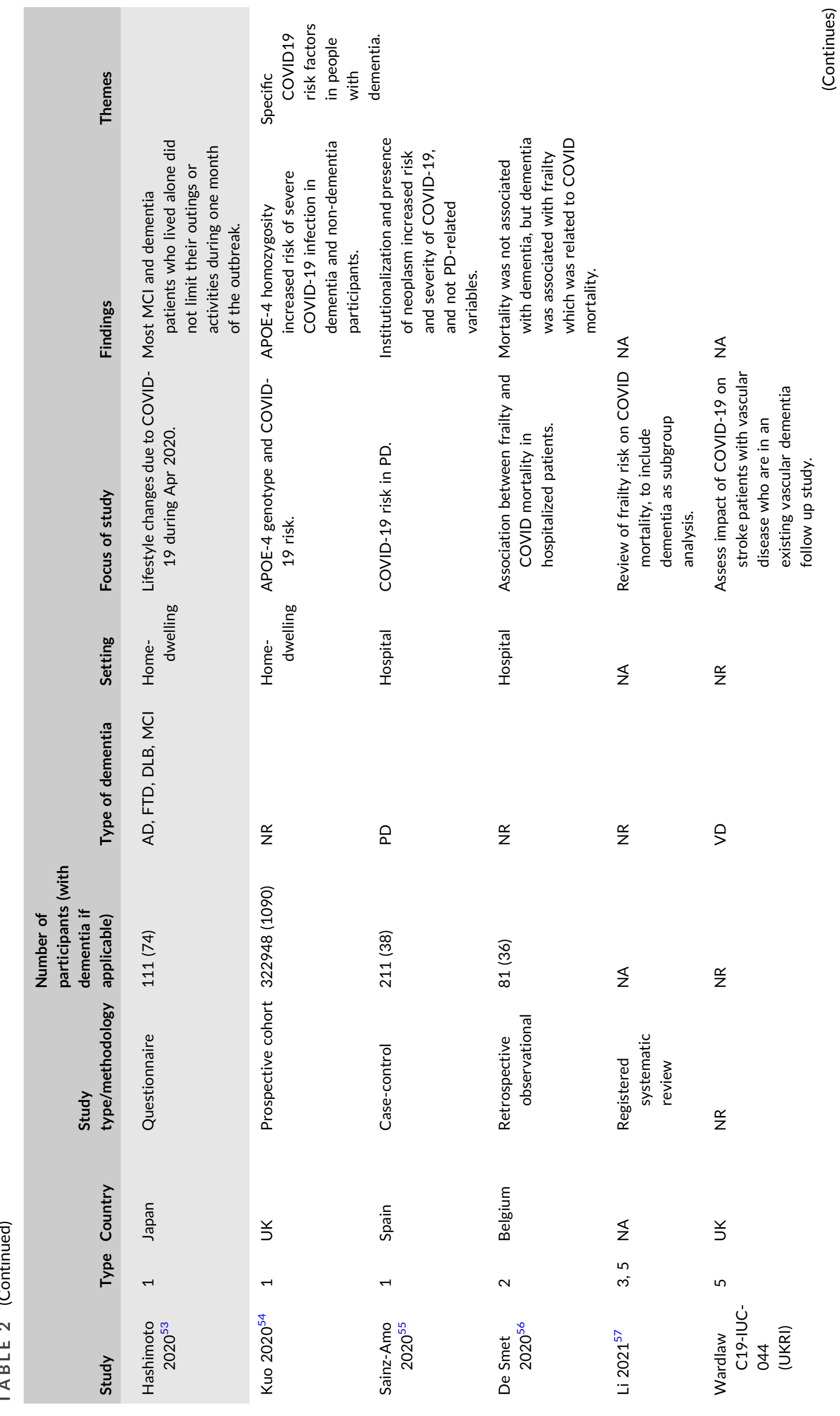




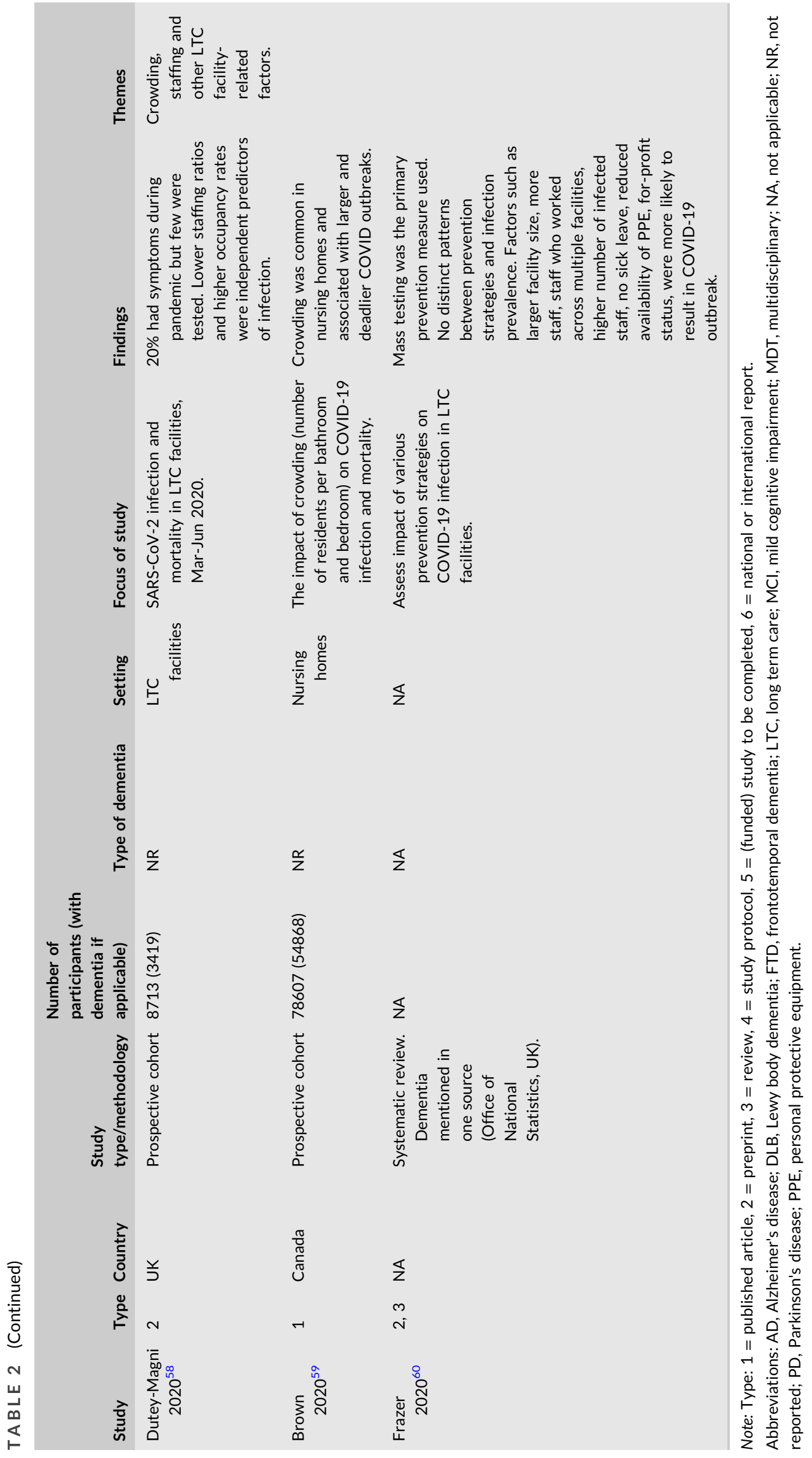


ili

总

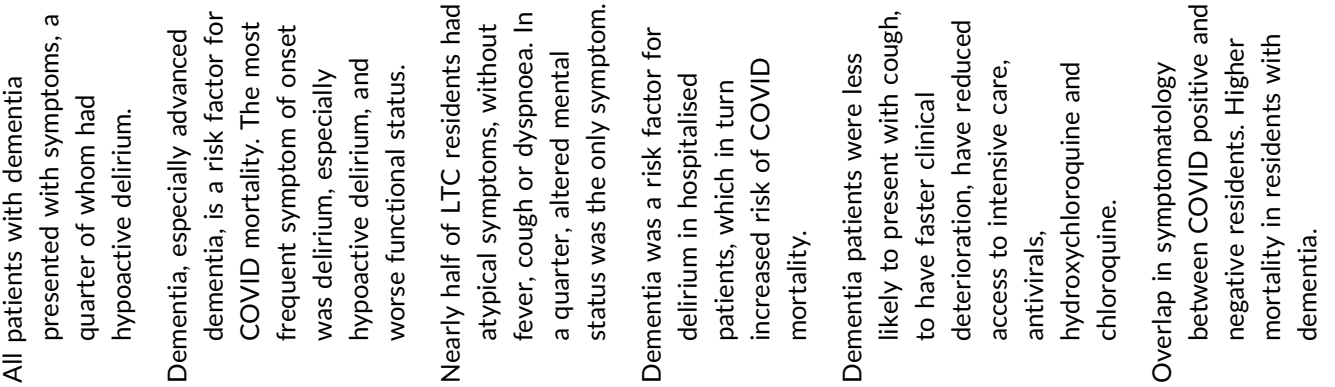

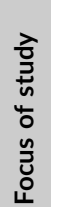

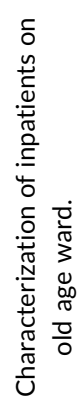
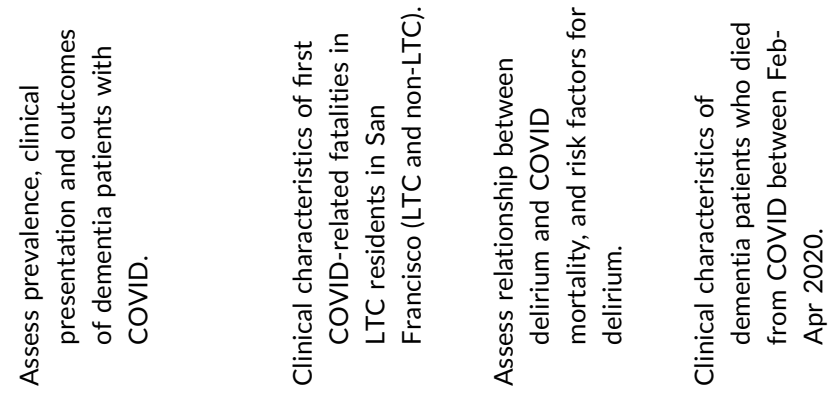

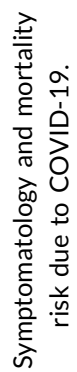

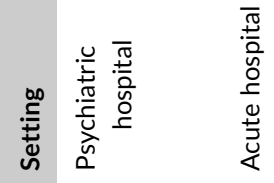
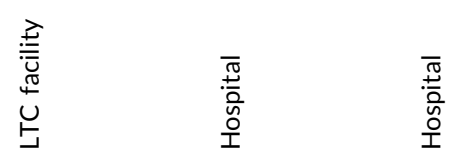

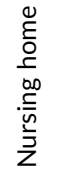

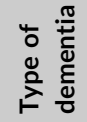

兄 品

兴

$\stackrel{\varrho}{z}$

$\stackrel{\propto}{z}$

$\stackrel{\wp}{z}$

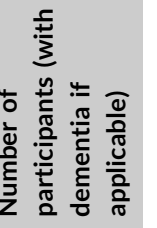

a

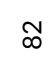

$\underset{\sqrt[n]{n}}{\stackrel{n}{a}}$

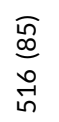

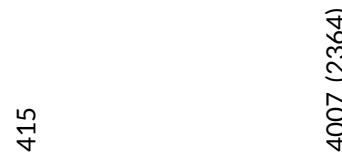

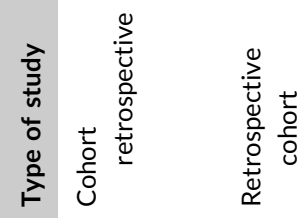

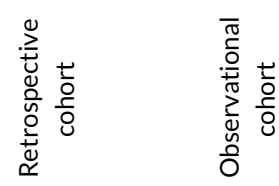

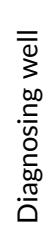

产 亭突

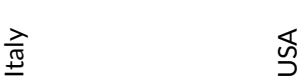

突离

곺

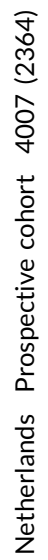

$\underset{m}{m}$

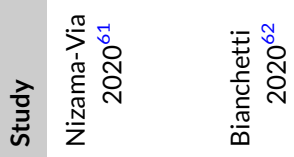

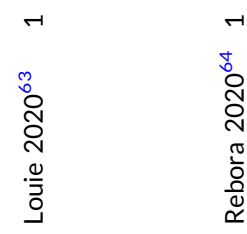

言芳

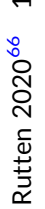




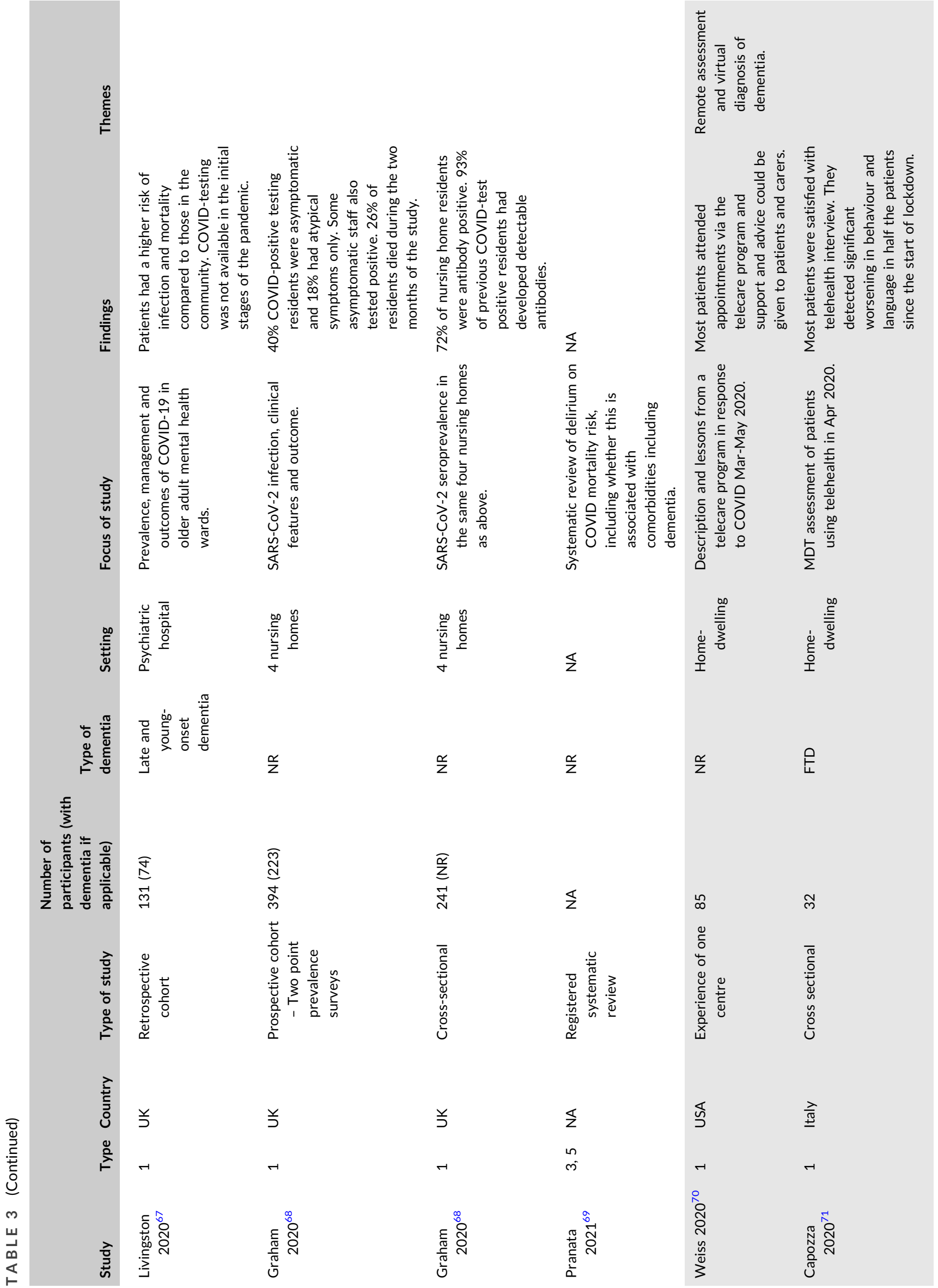




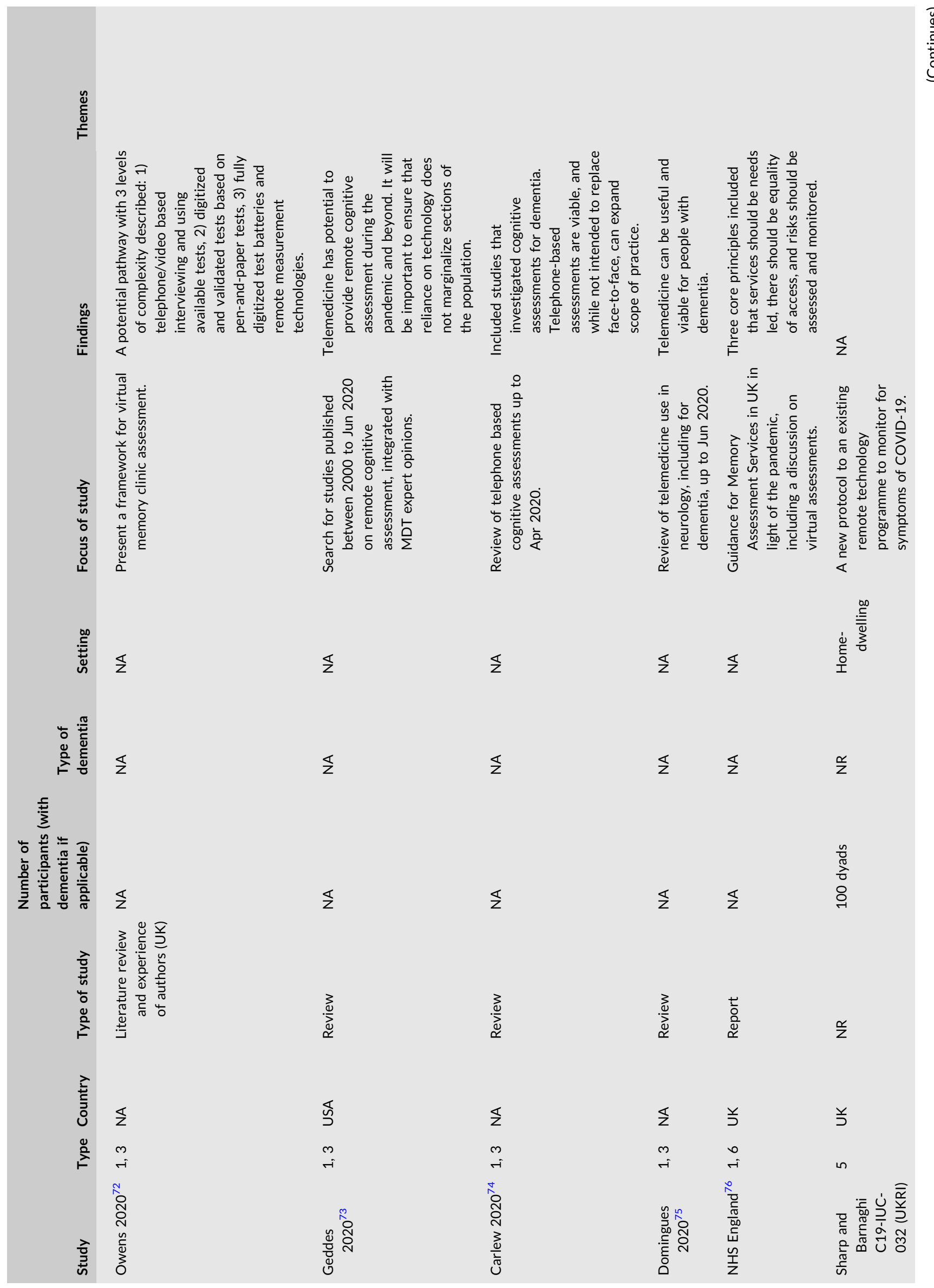




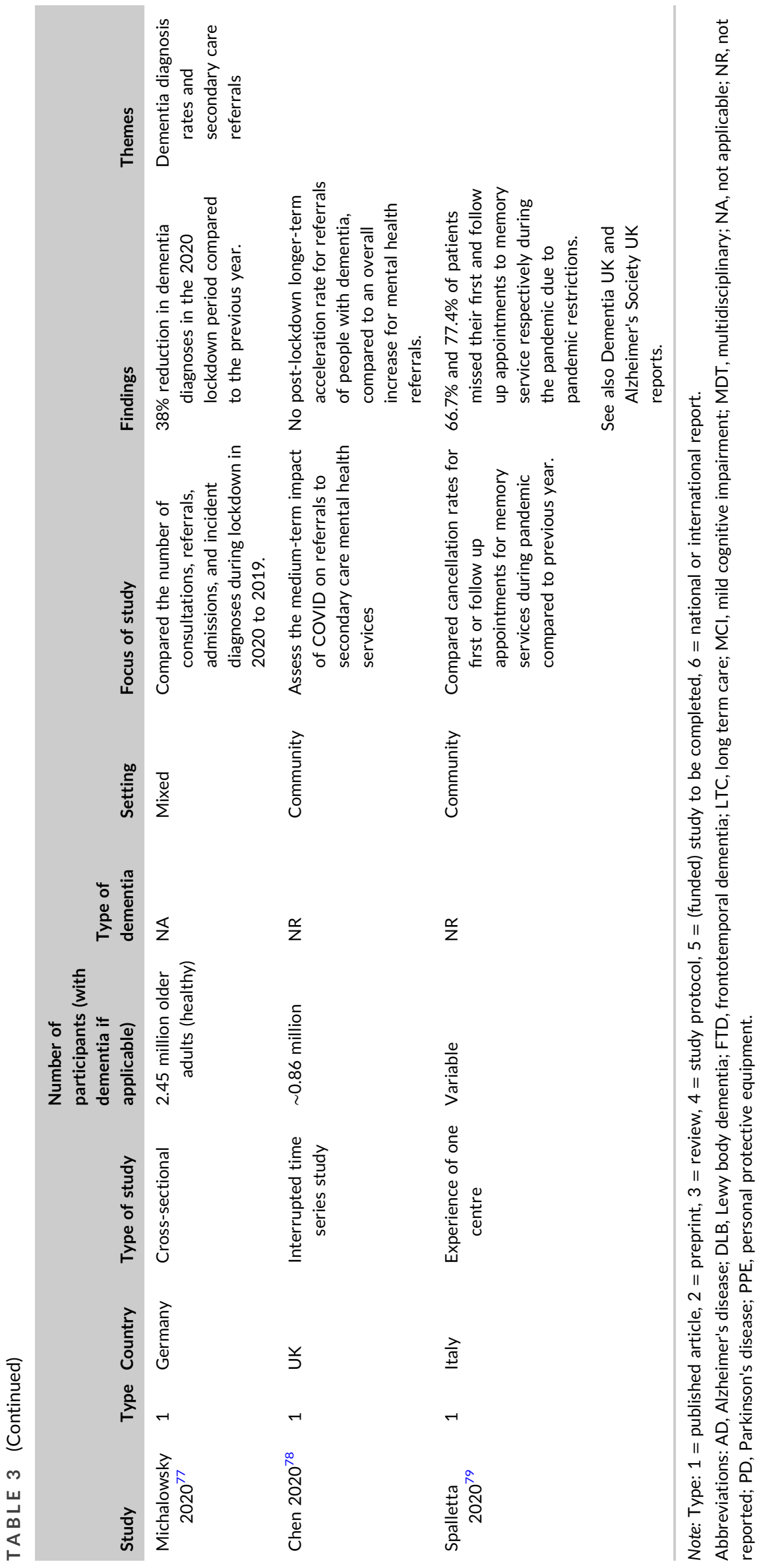


has the potential to worsen functioning and cognitive impairment. ${ }^{138}$ The potential impact of post-COVID syndrome on the dementia workforce and carers is also unknown. Members of the expert group were aware of NIHR and UKRI-funded studies on the longer term biological and health impacts of COVID-19, that is, post-COVID syndrome, to be announced in early $2021,{ }^{139}$ the findings of which may be relevant to people affected by dementia. Advocating for people living with dementia to participate in ongoing research projects that are monitoring post-COVID syndrome will be important, as will the inclusion of long-term care facilities as sites for recruitment.

As COVID-19 may increase dementia risk directly or by reducing cognitive reserve, ${ }^{140}$ it would also be important to review the biomarker evidence of progressive neurodegeneration or neuroinflammation in dementia following COVID-19 infection. Fluid biomarker studies in people with dementia during the COVID-19 pandemic would require implementation of procedures to minimise the risks to participants, staff and researchers. ${ }^{141}$

Treating Well: Ensuring access to the best treatment available (Table 4).

Primary care services provide healthcare for people affected by dementia in the community, but one UK survey found that most care home managers reported that general practitioners (GPs) were reluctant to visit care homes. ${ }^{4}$ In November 2020, the proportion of people living with dementia who received a medication review organised by their GP in the past 12 months decreased to $17.5 \%{ }^{133}$ from $20.7 \%$ in November $2019 .{ }^{134}$ The longer-term impact of these figures on the mental and physical health of people affected by dementia needs further investigation.

Teleconsultation used in memory clinics during lockdown ${ }^{80,81,87}$ was helpful for some carers, but others were uncertain about their purpose and usefulness. ${ }^{5}$ An adapted UK study (PriDem) found that many people living with dementia and their family carers were avoiding contact with primary health services and had mixed opinions of the value of telephone contact from primary care. ${ }^{88}$

Worsening of dementia-related behaviours seen during the pandemic, such as anxiety, agitation and psychosis, was associated with an increase in antipsychotic prescribing. ${ }^{95,94,96}$ Remote management, for example, via video and telephone, was possible and helpful for crisis and multidisciplinary team reviews, but only a small proportion of participants in these studies had dementia. ${ }^{86,135}$ More research is needed to explore how remote support can be optimised in health and social care services and assess the success of any transitions to remote technologies. Several studies are investigating remote delivery of psychosocial or physical interventions to help to improve wellbeing and behaviour (see 'Living well' domain below).

Reductions in access to services and the negative impact of the pandemic on dementia-related behaviour may have contributed to a rise in dementia-related emergency admissions amidst an overall decrease in psychiatric admissions to hospital. ${ }^{93}$ Patients with dementia had particular needs in hospital, as reported by a UK study, ${ }^{91}$ and required high levels of medical, nursing and dietician input and early discussions relating to end of life care and resuscitation status.
Although older adult psychiatric/mental health wards in London introduced swift adaptations such as isolation, testing and oxygen treatment, these efforts were hampered by delayed access to Personal Protective Equipment (PPE) and COVID-19 tests (compared to local general hospitals). ${ }^{67}$ There have also been inappropriate 'blanket' do not attempt resuscitation (DNAR) decisions and restricted access to healthcare affecting care homes in England, which led to national investigation by the regulator. ${ }^{126}$ Similar concerns about unequal access to treatments were echoed in a US study. ${ }^{65}$ These measures are not supported by findings from one study in China, which found that hospitalised patients with dementia had better outcomes than patients without dementia, related to earlier hospital admission and care. ${ }^{92}$

Four centres ${ }^{80,82,85,83}$ published their experiences of the impact of the pandemic on clinical research activities. There was a reduction in patient recruitment and in-person visits, but participation rates in ongoing studies remained high. Centres adapted to the pandemic by introducing COVID-19 symptom monitoring, PCR testing of staff and participants, PPE use and/or teleconsultation. The longer-term impact of COVID-19 on research recruitment and participation, including initiatives such as NIHR Join Dementia Research (www. joindementiaresearch.nihr.ac.uk/) needs further investigation. It will also be important to obtain data on the impact on dementia researchers, especially early career researchers who may have lost opportunities for funding and support, and have experienced changes to academic workplaces, such as laboratories and universities.

Supporting Well: Providing personalised care and support to carers at home and people in care homes (Table 5).

At least six funded studies in care homes are ongoing (Table 5) to further understand the impact of COVID-19 in UK care homes and develop future guidance and best practice approaches on visiting, protection of human rights, management of outbreaks, reducing social isolation and antimicrobial prescribing. Use of email, video and phone calls to contact family members and other care home residents may help reduce loneliness and improve wellbeing ${ }^{106,107}$ and remote input from healthcare professionals may help to support care home staff (HammondCare International Ltd, UKRI). Further research is needed to assess the extent to which all care home residents can access the potential benefits of remote support and communication.

The pandemic is also having a negative impact on the mental and physical wellbeing of family carers (see Preventing Well, Table 2), many of whom are unpaid and have experienced changes in care responsibilities (increased care hours) with financial implications, suggesting that financial assistance is a potential source of support. ${ }^{49}$ Studies and reports of home care services found that increased levels of carer stress could be mitigated by visiting care workers ${ }^{112,110}$ although family carers were often concerned about staff availability and potential risk of infection, so sometimes did not continue with such services. ${ }^{142,113,17}$ Other family carers also worried whether home care services would be available in future if they refused them, ${ }^{142}$ especially as they feared reductions in support and missed the continuity of a familiar home care worker. Six funded UK studies will investigate the impact of COVID-19 on dementia care at home to 


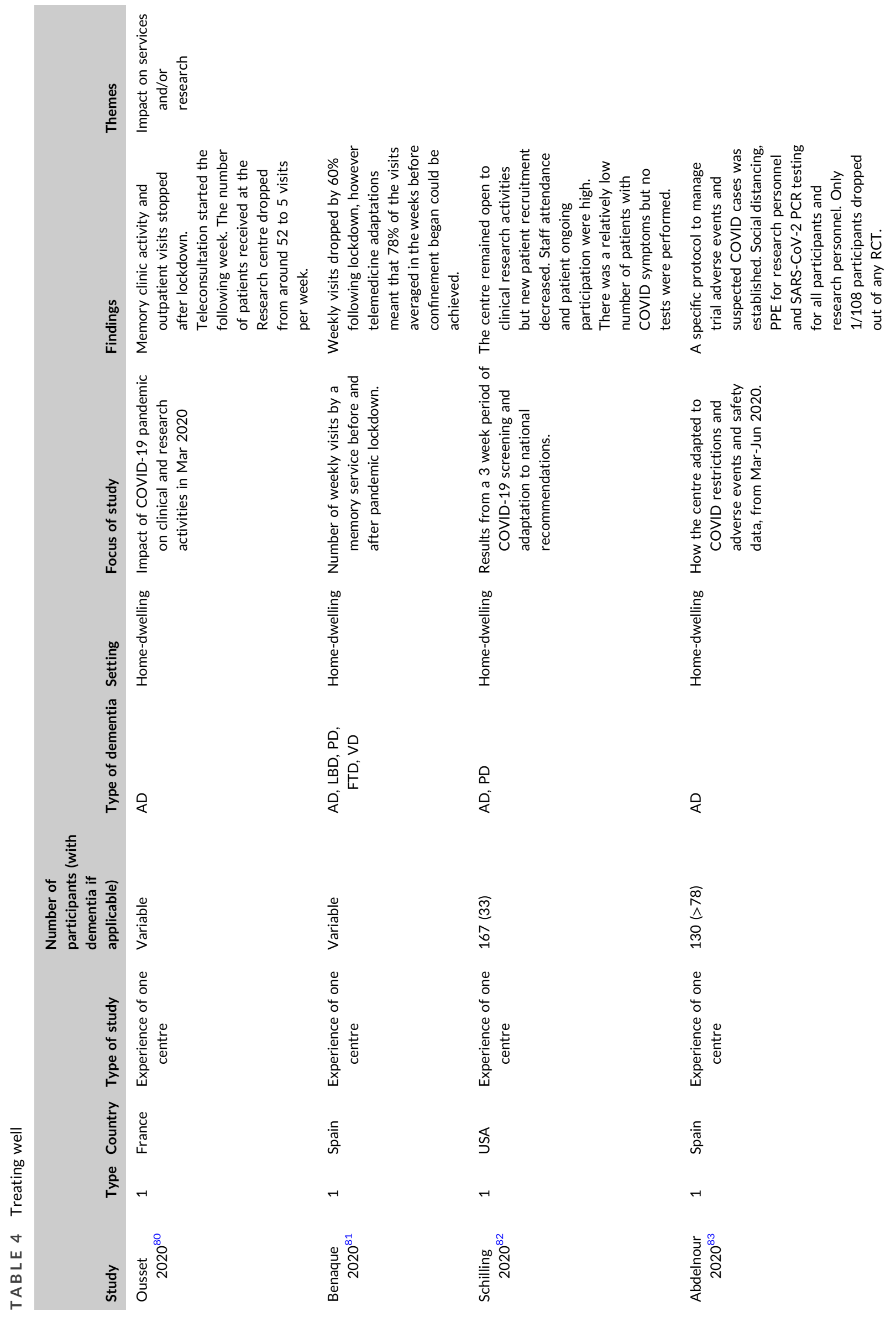




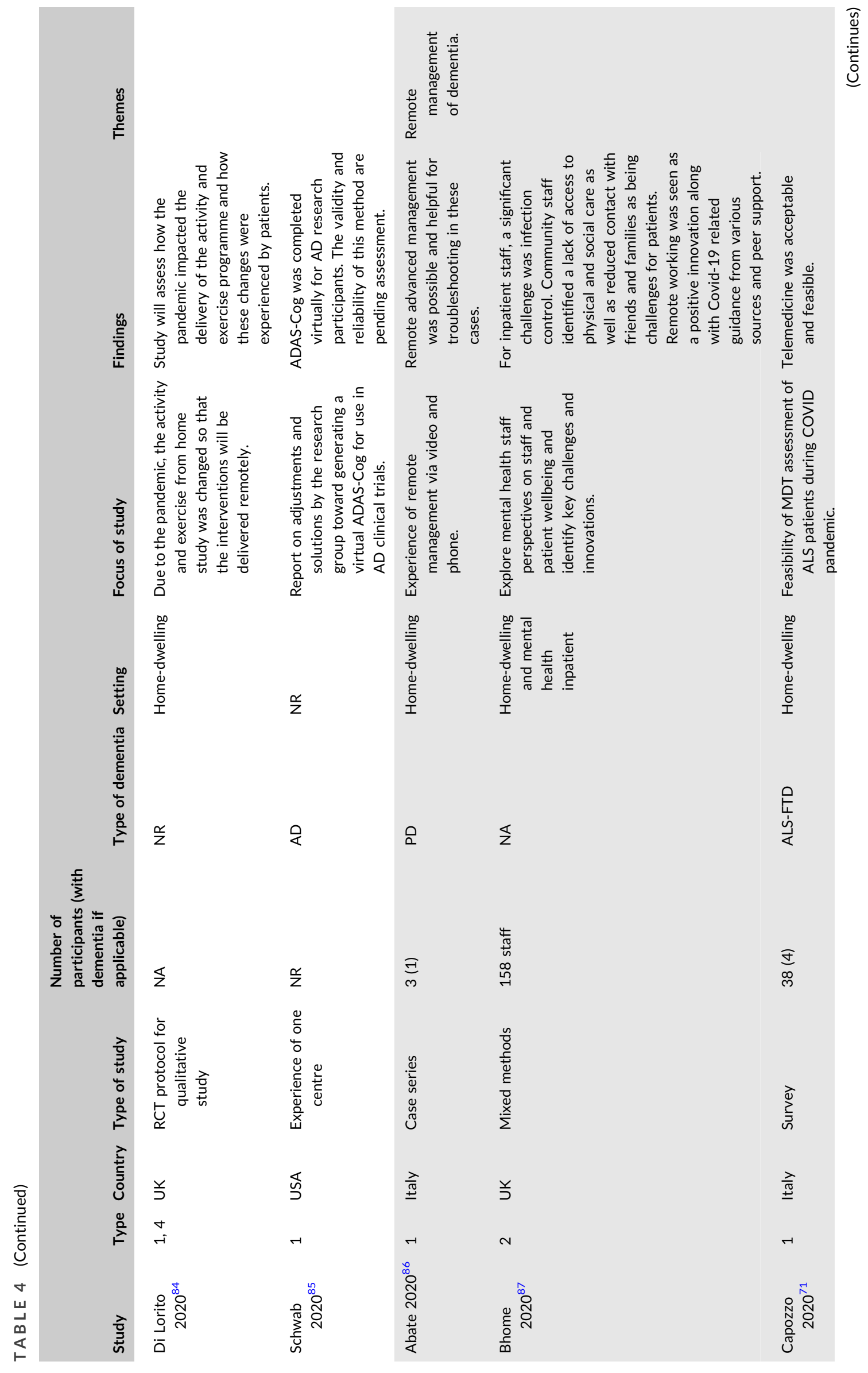




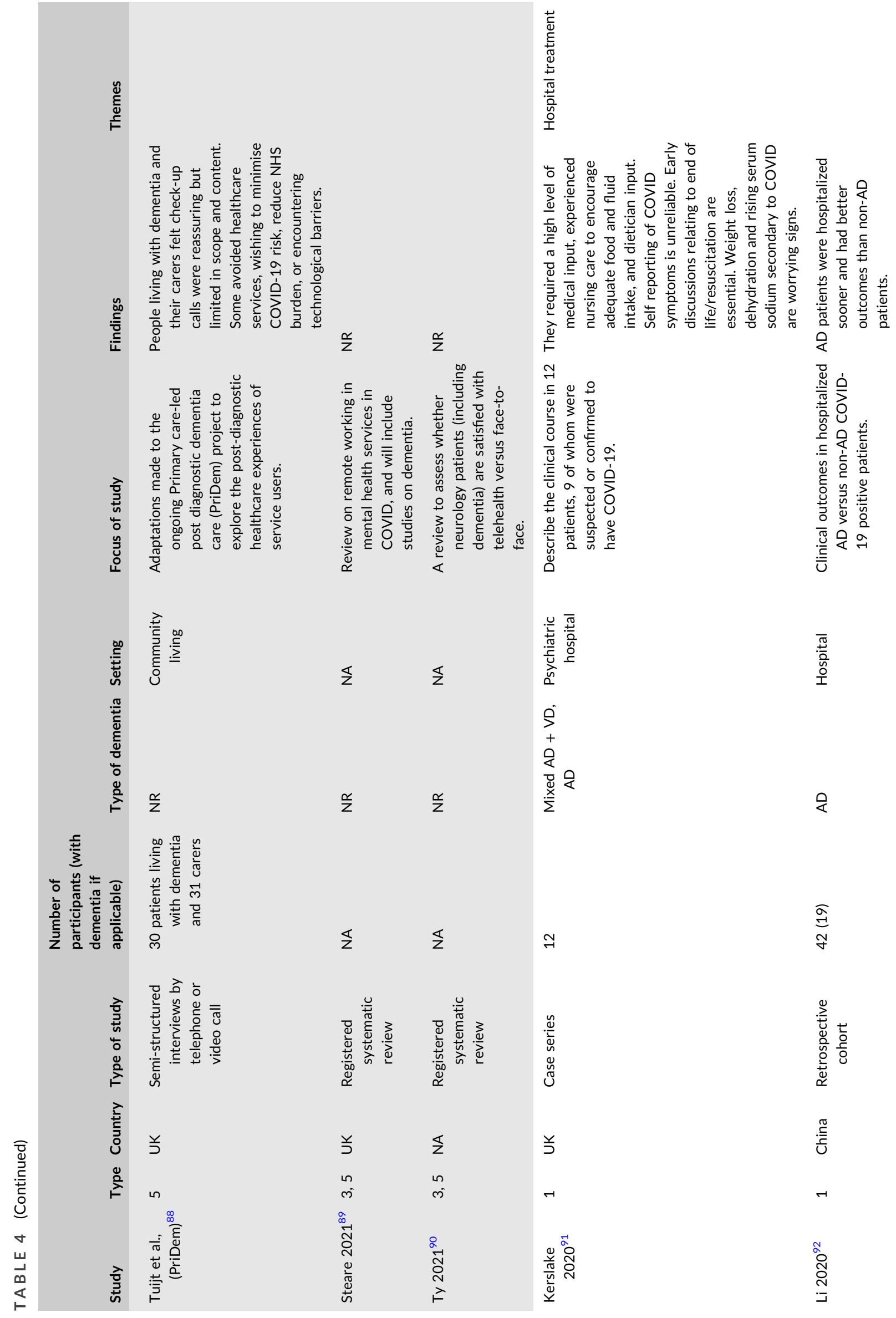




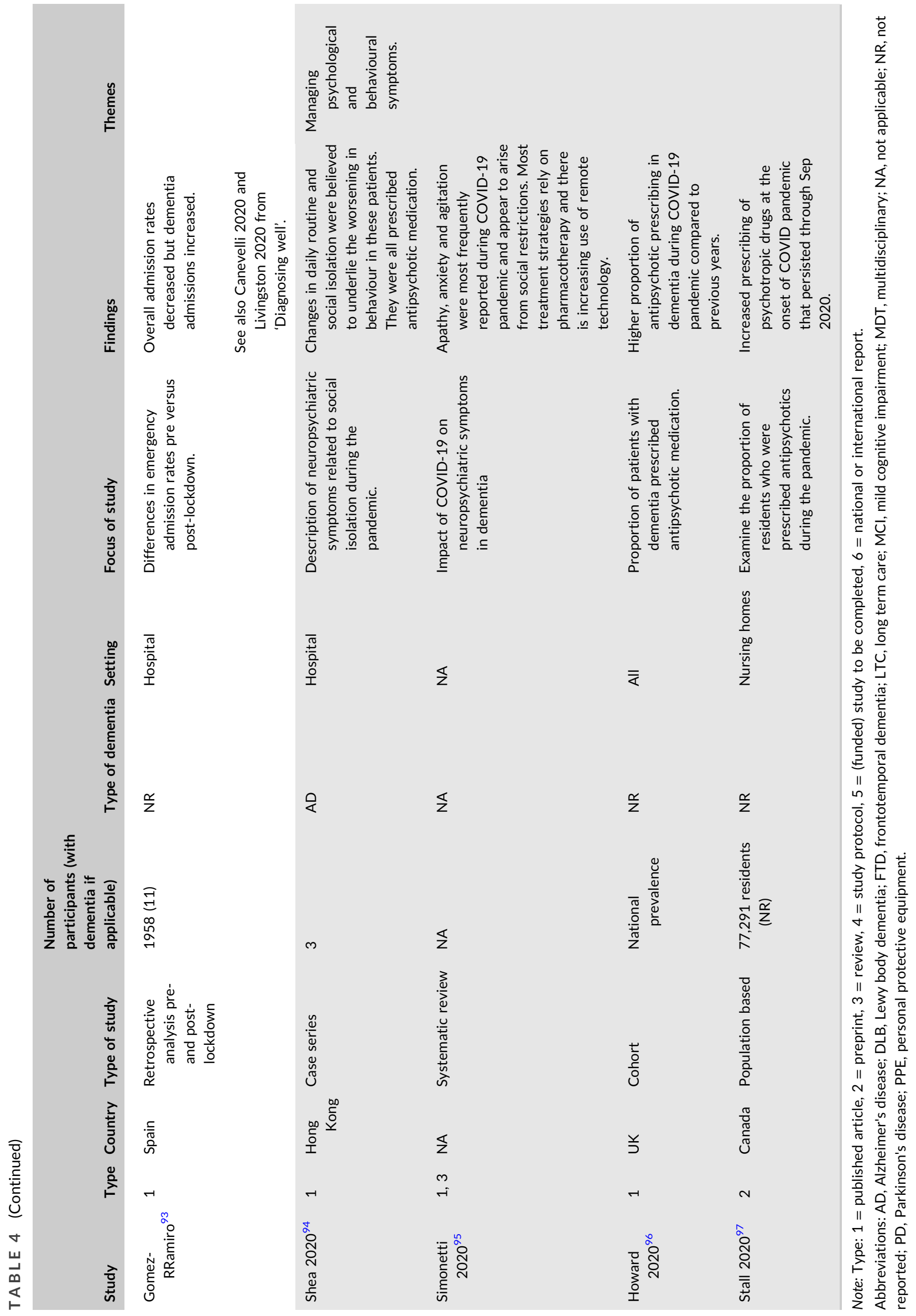




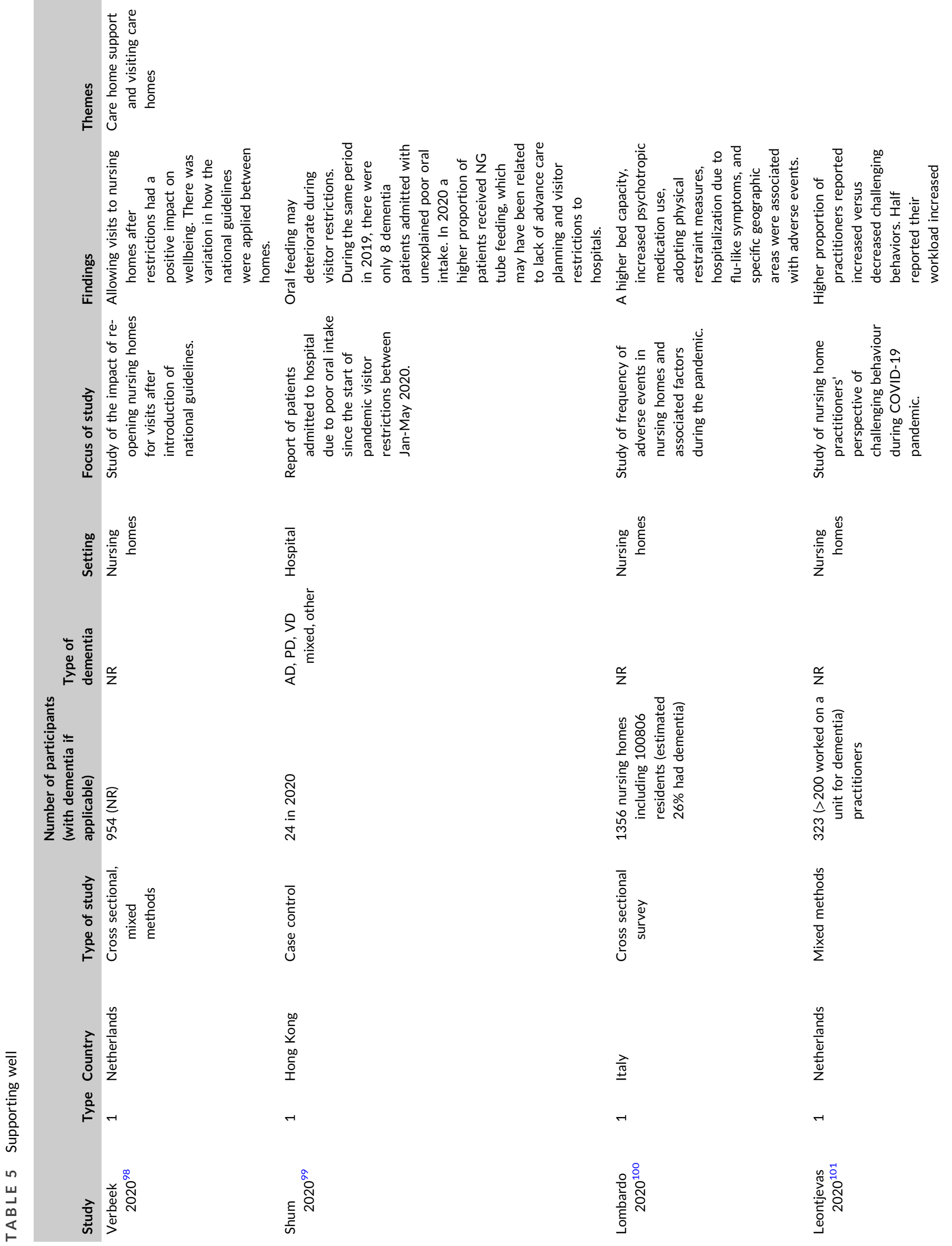




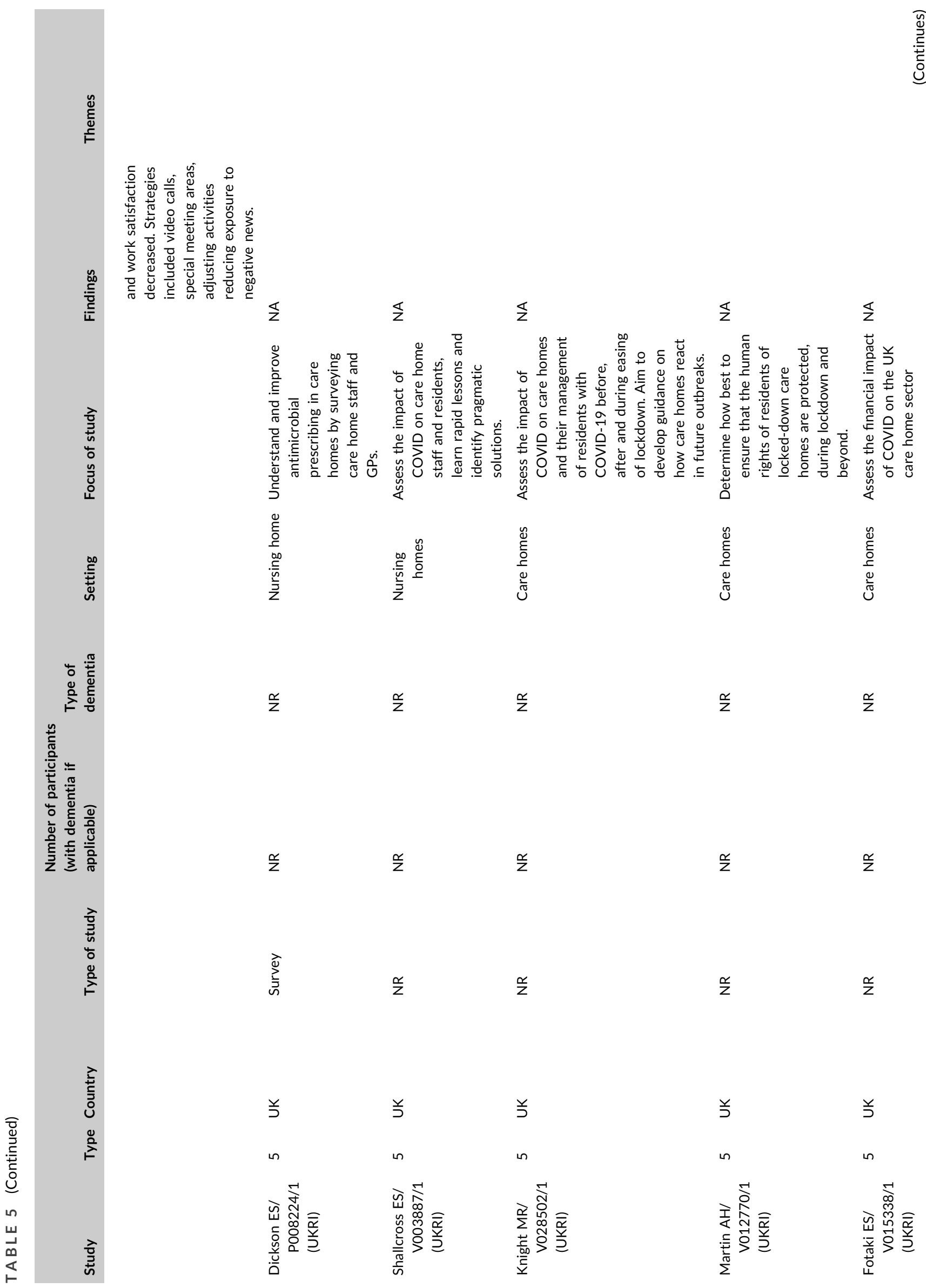




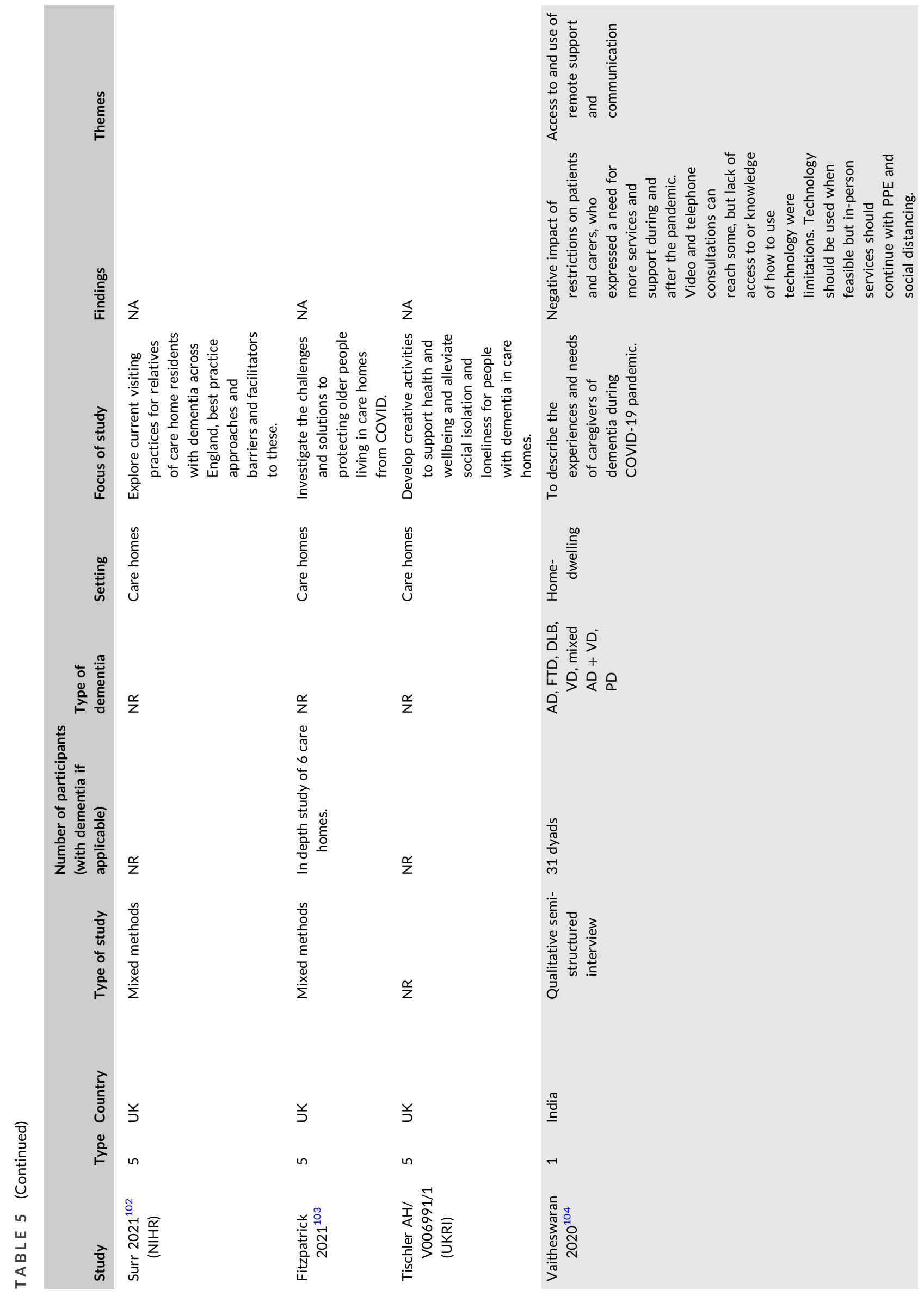




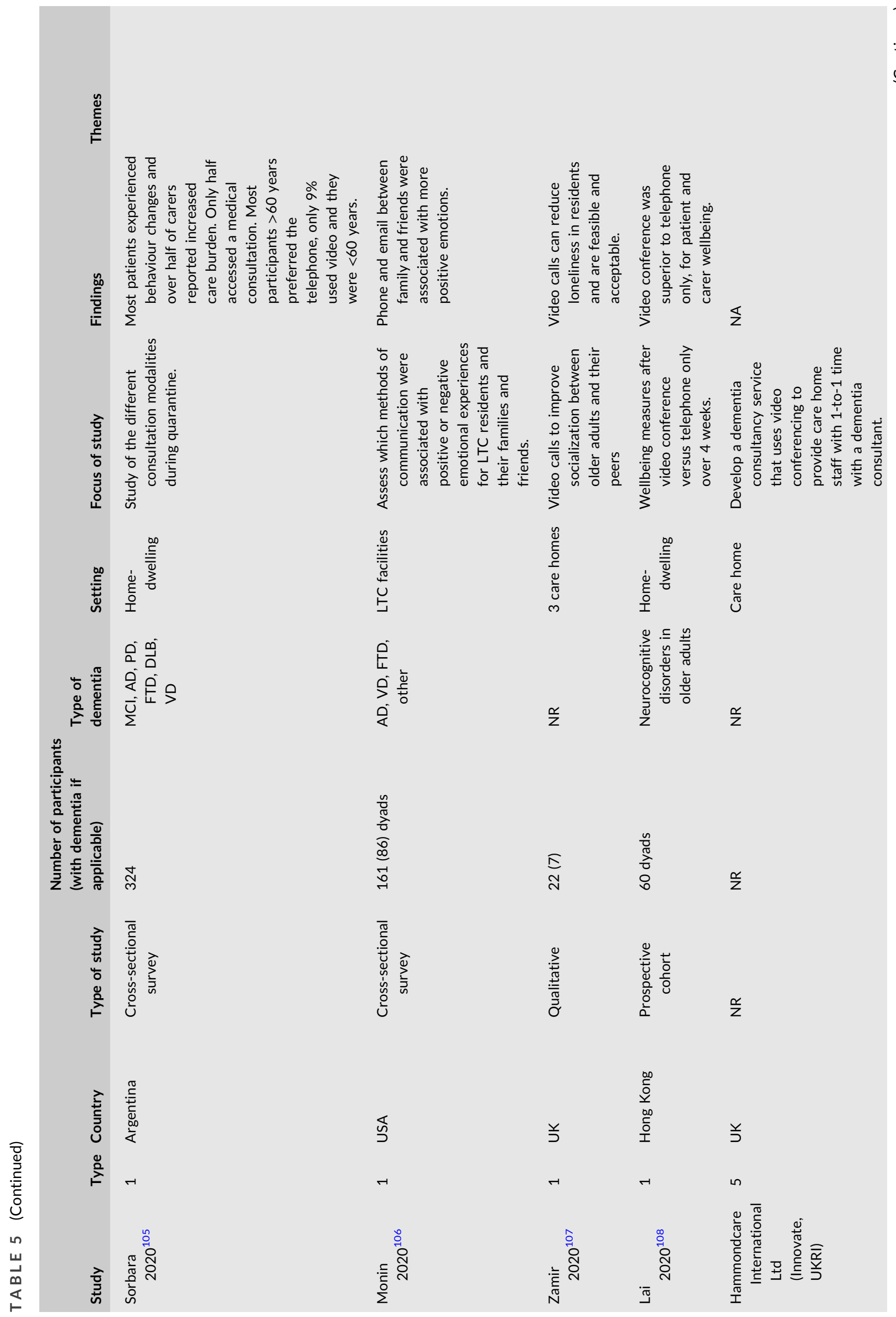




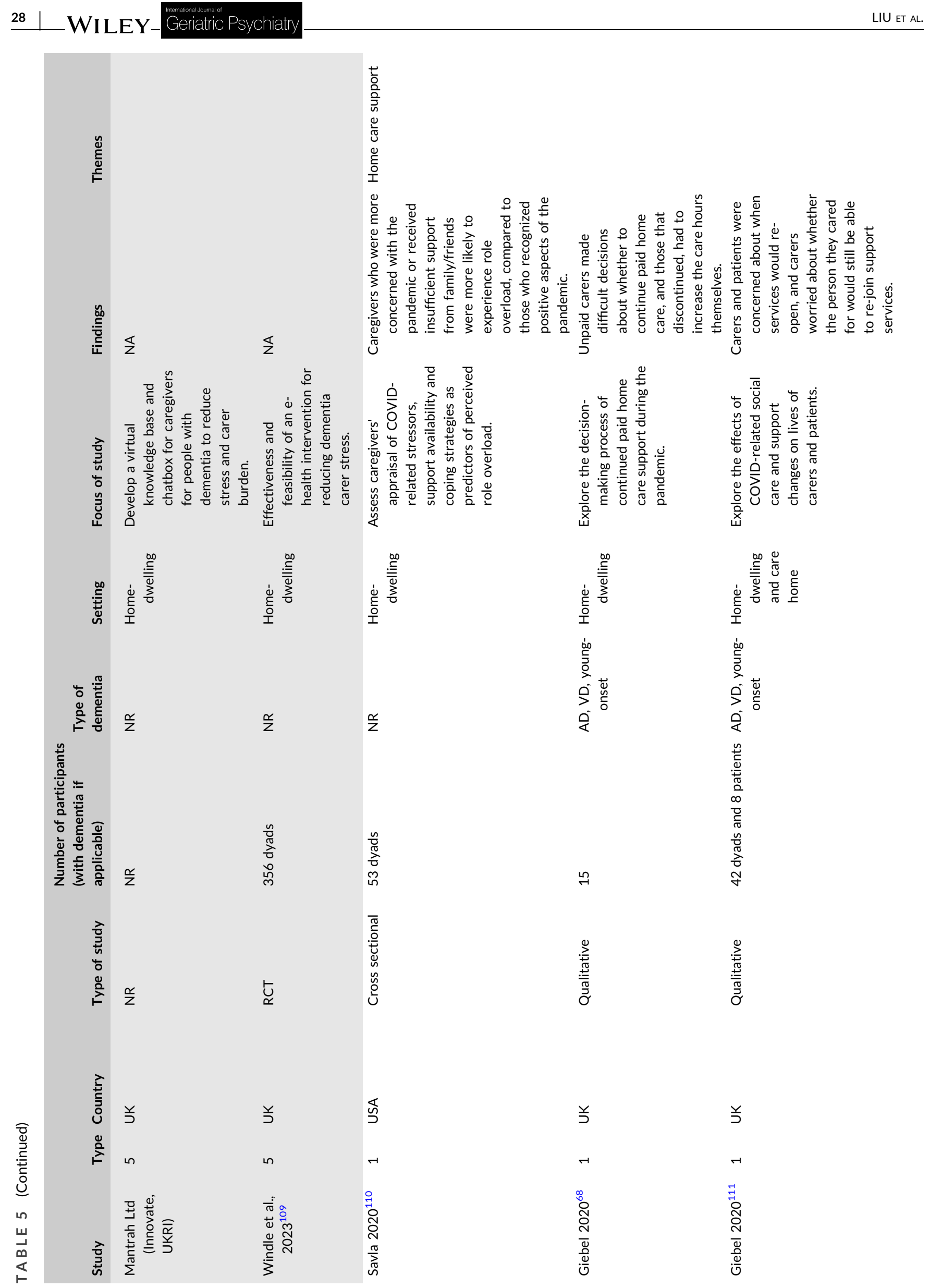




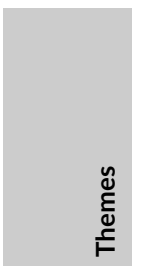

递

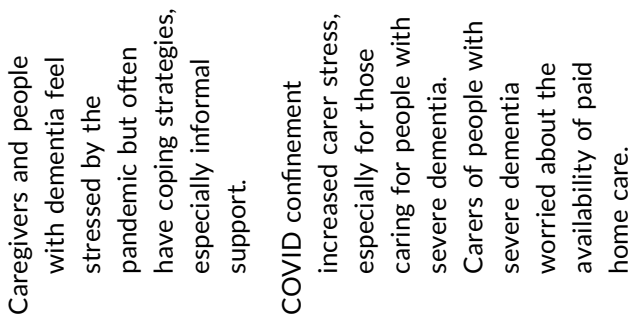

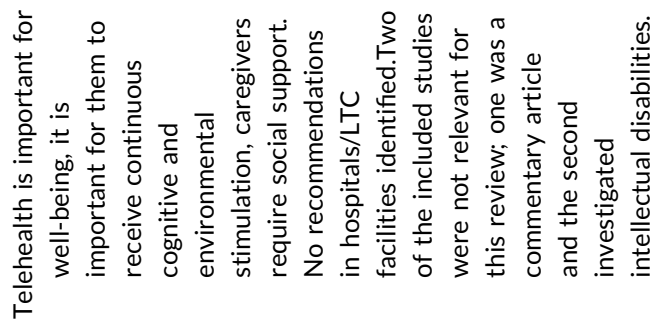

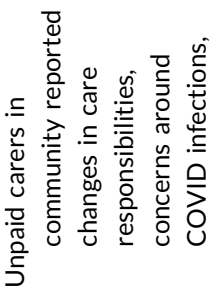

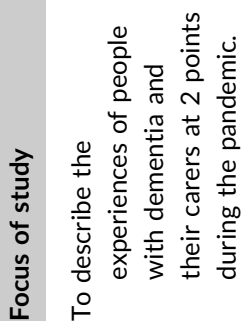
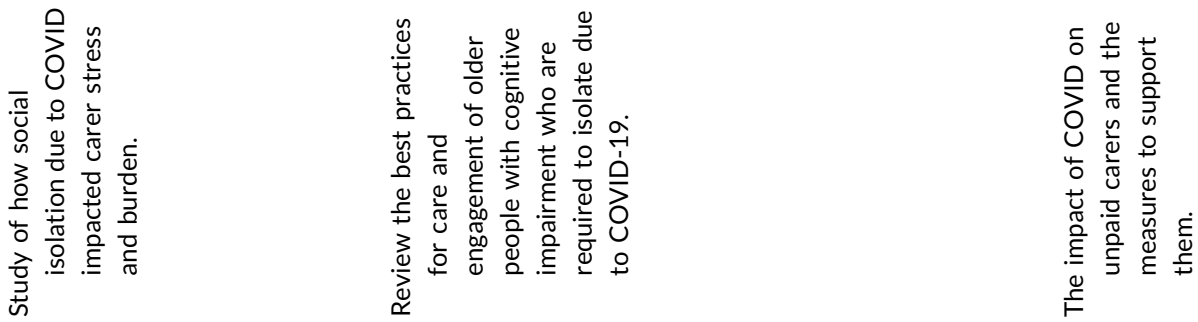

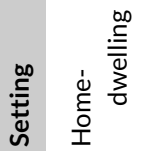<smiles>[13CH][13CH]</smiles>

竞: $\frac{\alpha}{z}$ \&<smiles>[13CH][13CH]</smiles><smiles>[Li][13CH]=[13CH]</smiles><smiles>[C]1[CH]C=C1</smiles>

$\stackrel{\aleph}{z}$

$\frac{n}{0}$
$\frac{0}{0}$
$\frac{0}{0}$
$\infty$

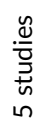

$\frac{n}{\frac{n}{9}}$

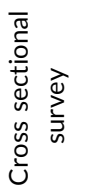

$\frac{3}{20}$<smiles>CCC</smiles>

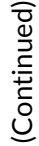

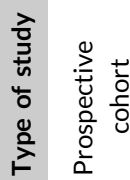

辛

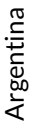

范

$\frac{\frac{n}{3}}{\frac{0}{\frac{0}{2}}}$

i

웡 


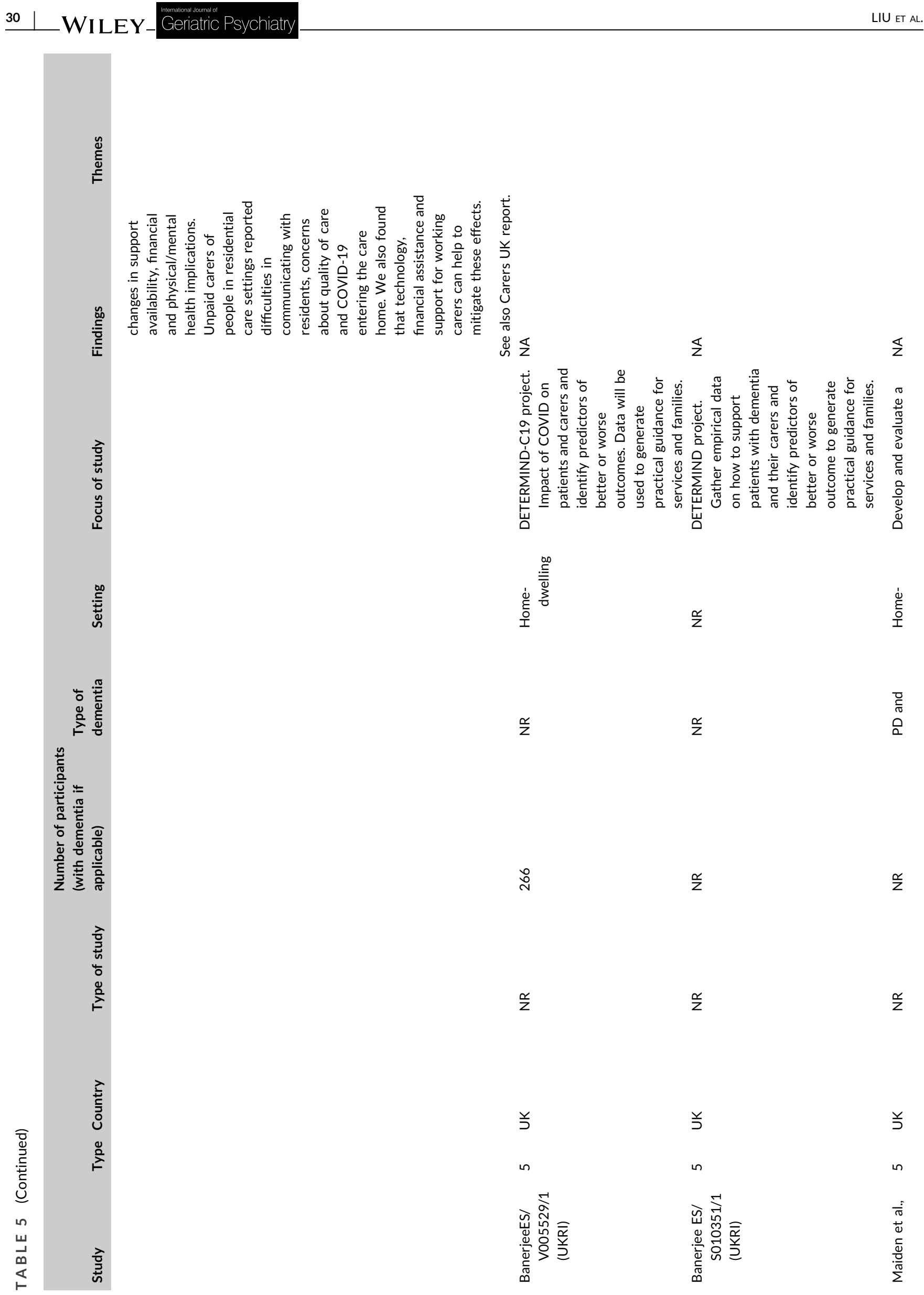




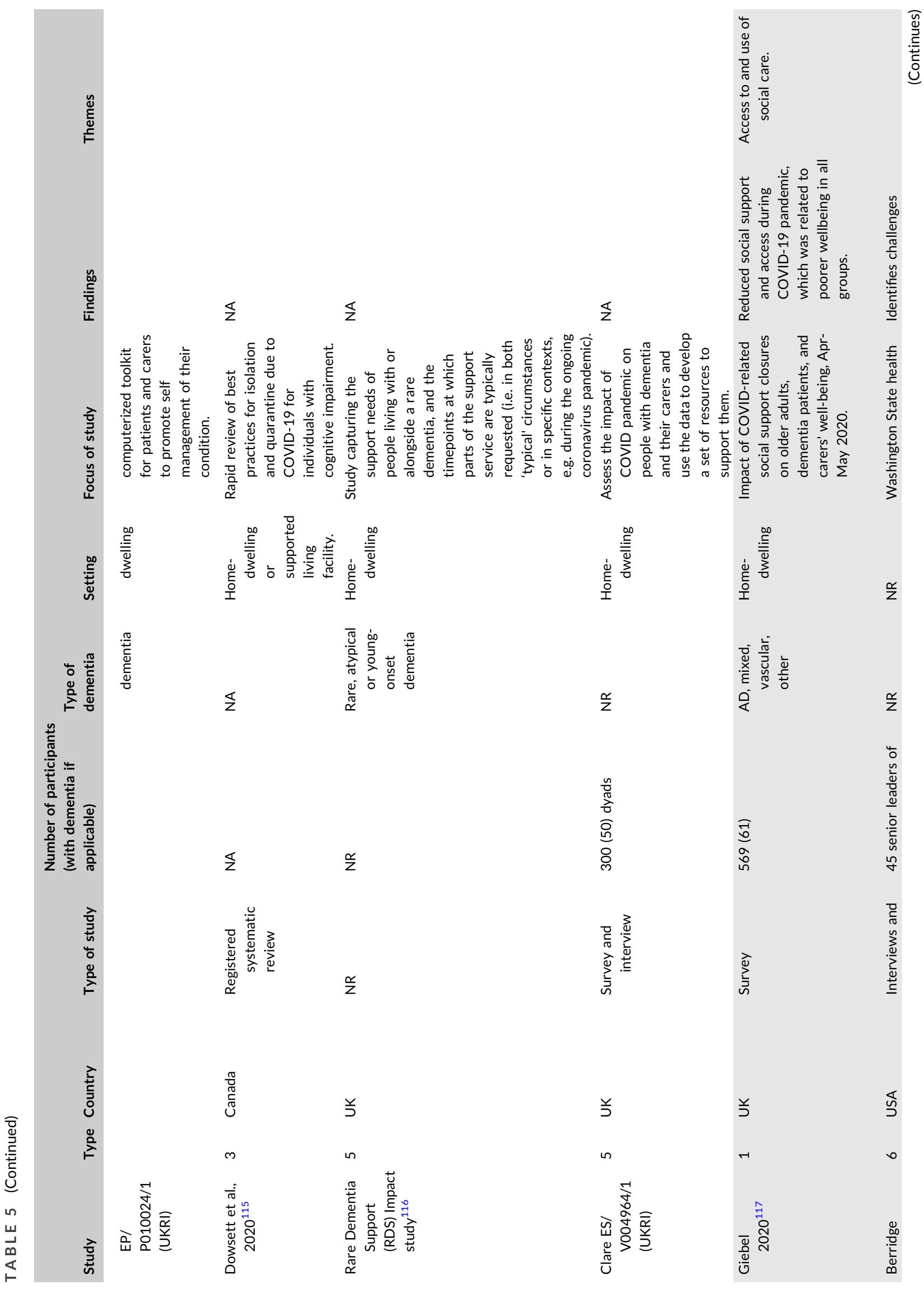




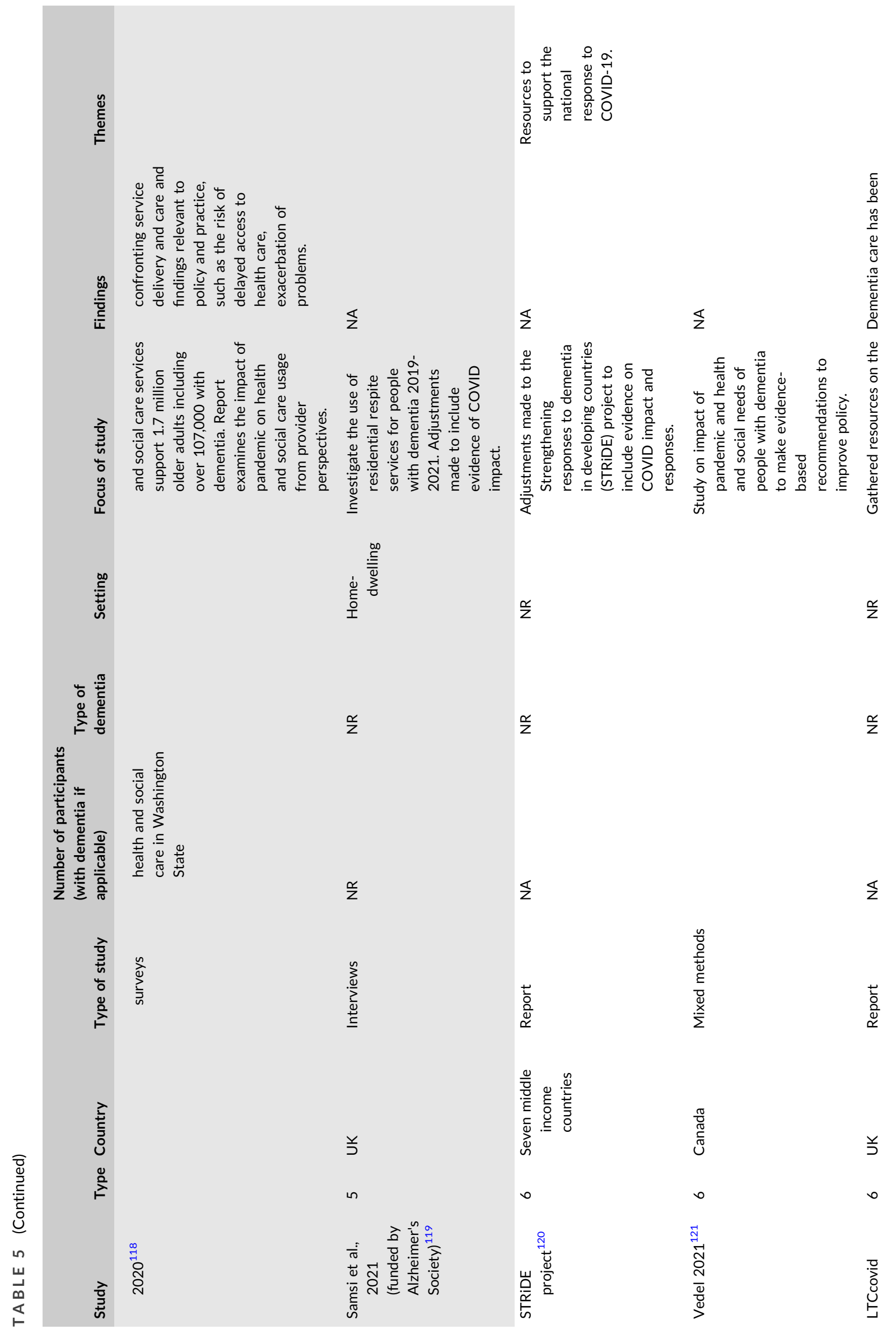




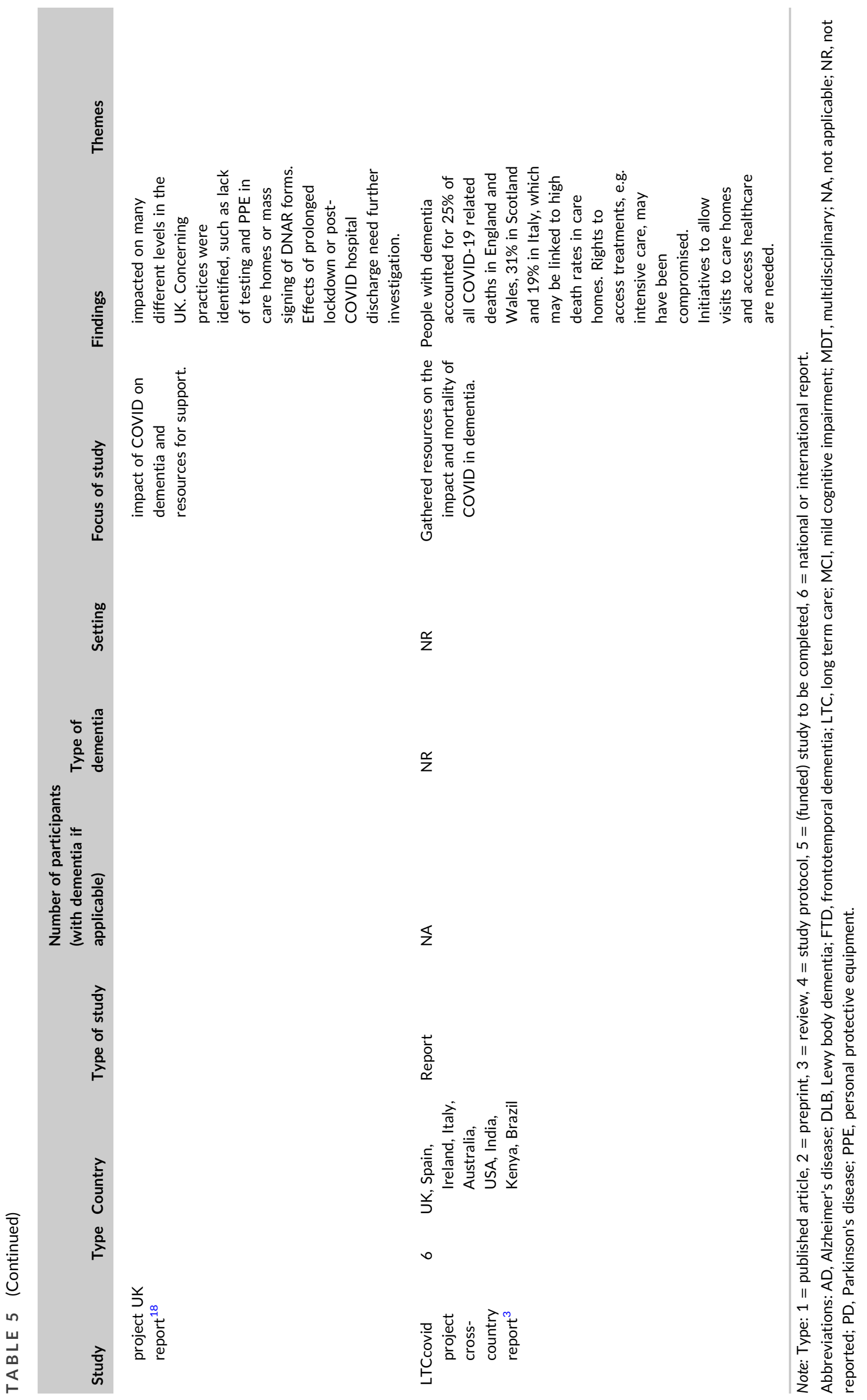




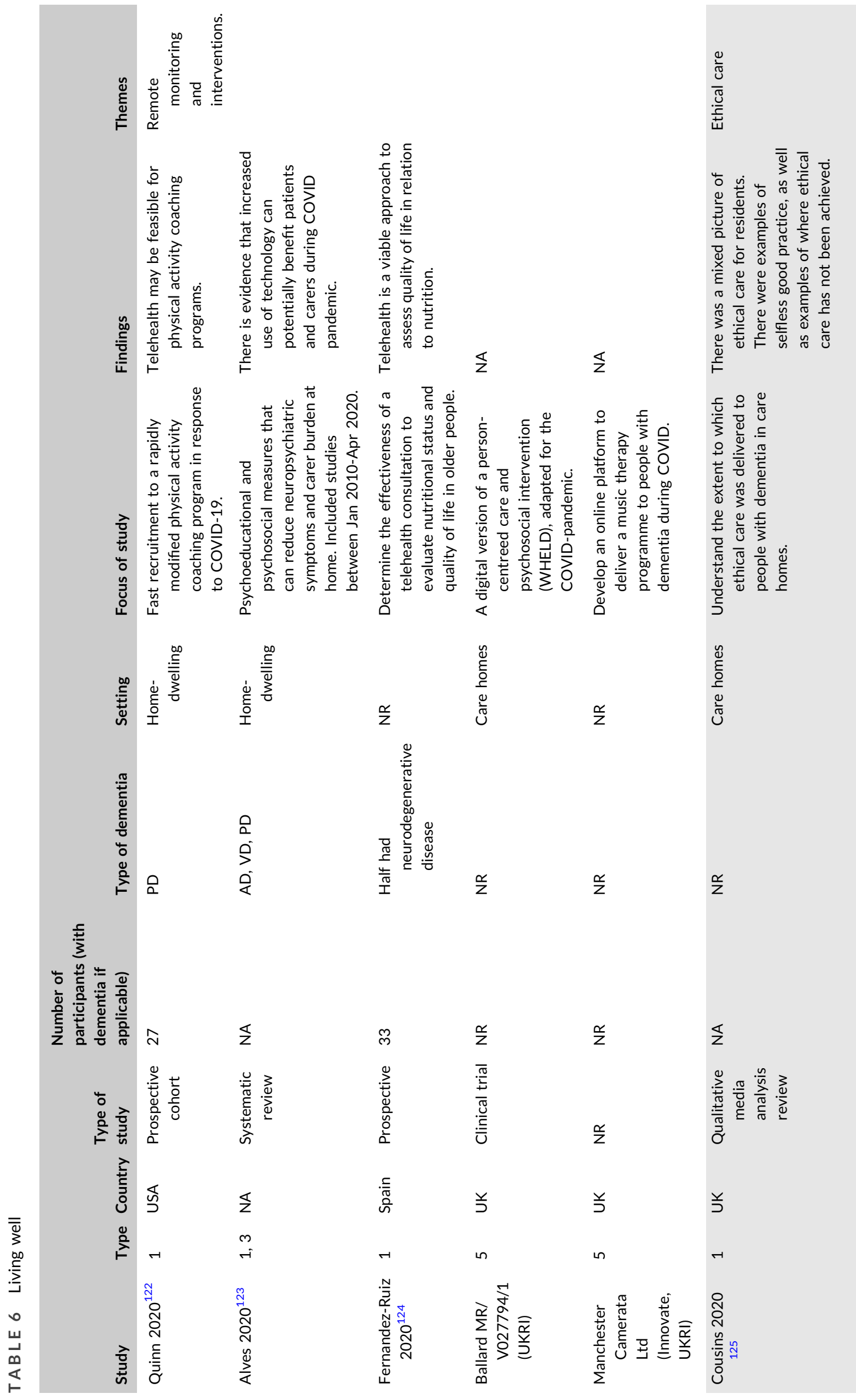




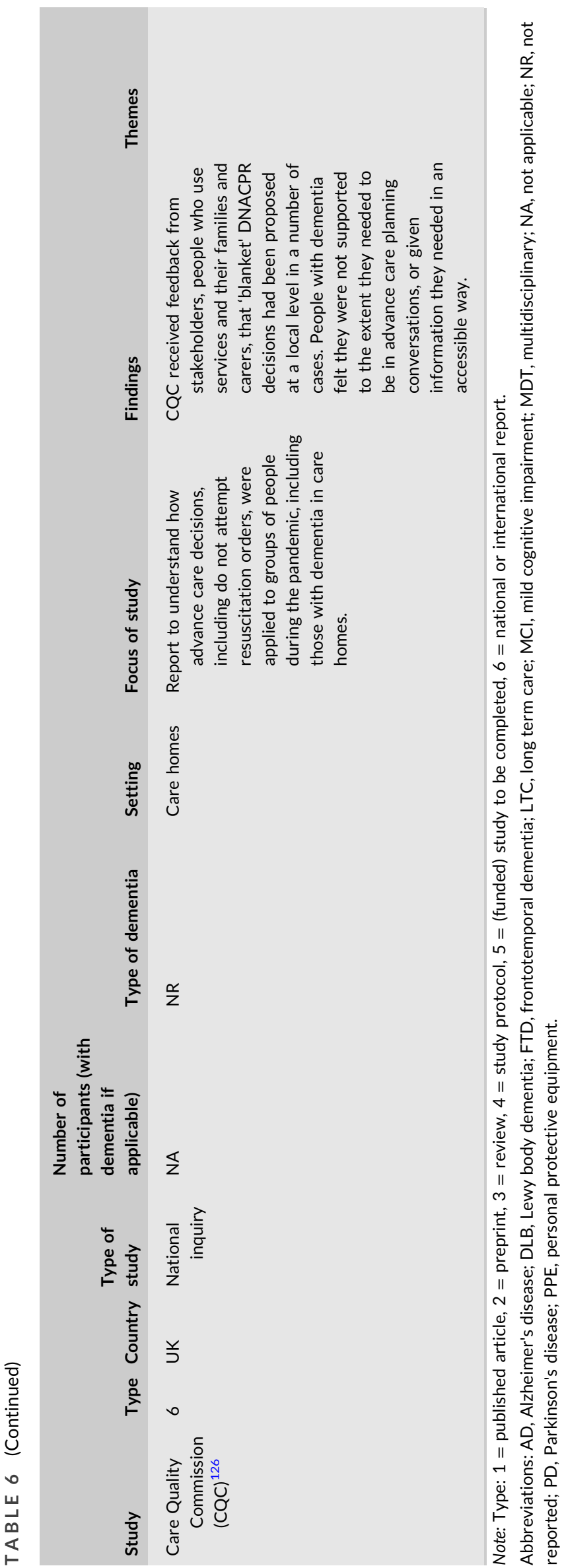

identify predictors of better or worse outcomes, identify best practices and develop guidance, and one study (part of the Alzheimer's Society PriDem project) is investigating the role of family carers in managing risks of harm and of loss of autonomy. ${ }^{143}$

Studies that explored the use of remote communication technologies at home found that a substantial proportion of people living with dementia were unable to access remote consultations, possibly related to lack of access, knowledge or confidence to use the technology. ${ }^{104,105}$ People's preferences also varied. ${ }^{105,108}$ A partnership between UK DRI CR\&T, the Alzheimer's Society and University of Worcester has built a digital resource to help groups and individuals in the UK who support people with dementia set up local online networks to replace the pre-COVID face-to-face meetings (www. communitymakers.co), and two UK funded studies (Mantrah Ltd, UKRI $^{109}$ NIHR) are developing digital or online interventions for families caring for someone living with dementia to reduce carer stress.

Only one published study reported findings relating to reduced access to and use of day services and respite care during the pandemic, ${ }^{111}$ although a number of studies relating to social care in the UK are planned or ongoing, such as a UK study that started before the pandemic on the use and experiences of residential respite services for people living with dementia and has continued during the pandemic. ${ }^{119}$ The ability of respite and daycare services to survive and 'bounce back' is important to understand as these services provide vital support for people with dementia and their carers. Several ongoing and completed broader UK studies on the impact of COVID-19 on social care services and the social care workforce are summarised in more detail in Table S2.

Lastly, several dementia-related resources and projects have been set up or adapted to support the national responses to COVID19 in the UK, ${ }^{117}$ Canada, ${ }^{121}$ and internationally ${ }^{3,10}$; including middleincome countries. ${ }^{120}$

Living Well: Optimising the lived experience of dementia (Table 6).

Published and ongoing studies on the potential of technology to deliver physical, psychoeducational and psychosocial interventions remotely to people with dementia; ${ }^{122}$ Alves et al., $2020^{124}$ (Ballard; Manchester Camerata Ltd, NIHR) will offer insight into the acceptability of telehealth for those with more severe cognitive problems. Further research on the remote delivery of social care or befriending initiatives would also be important. The ethics of care provided to people with dementia in care homes were considered in two publications (Care Quality Commission ${ }^{126,125}$ Studies addressing the impacts of reduced social care services on people with dementia have been noted in the previous domain 'Supporting well'.

Ongoing studies are assessing physical activity ${ }^{48}$ and deconditioning in dementia during the pandemic, ${ }^{84}$ and it would be important for future research to investigate the rehabilitation needs of people affected by dementia who are diagnosed with post-COVID syndrome 


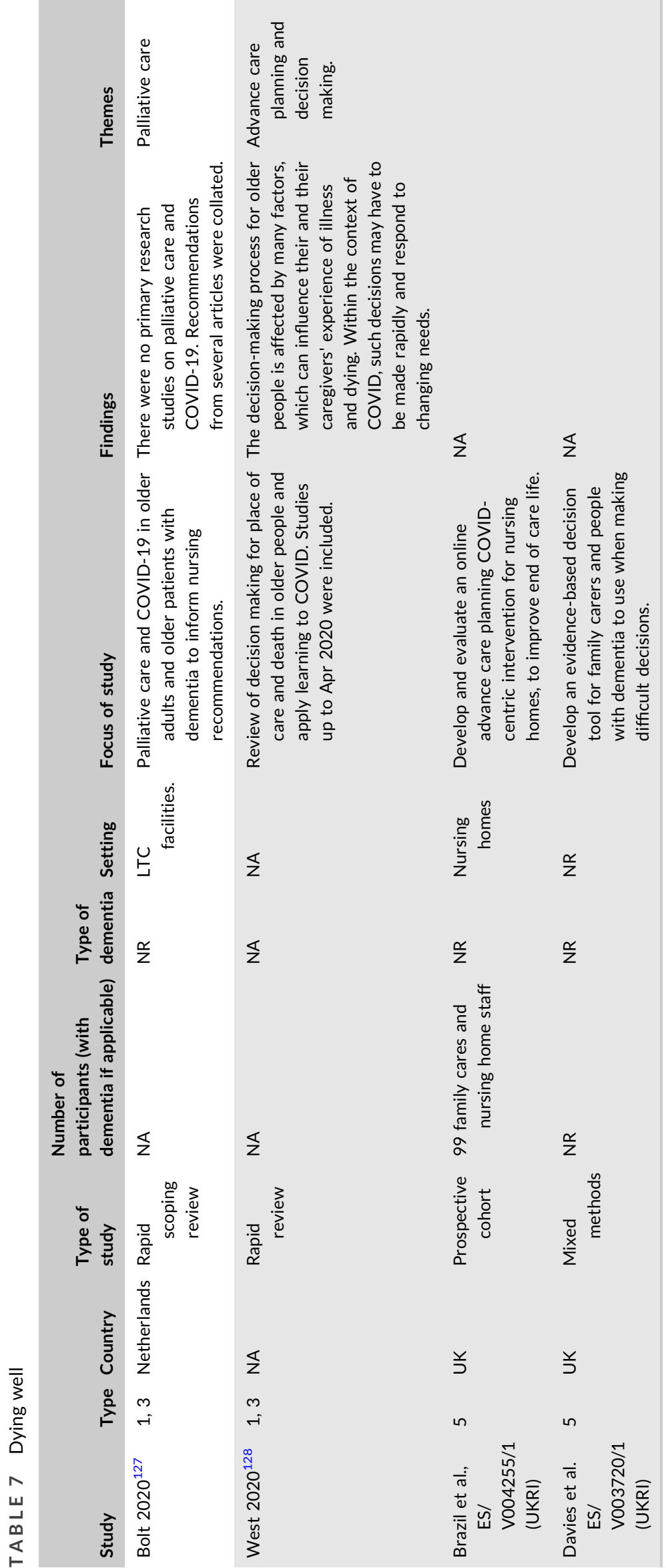


B ox 1 Summary of findings and consensus directions for future research

Findings from previous/current research

Directions for future research

Preventing well:

- Negative impact of COVID pandemic on cognitive, mental and physical health in people with dementia and their carers. Many family/friend carers provided more care, with financial implications.

- Impact of COVID on the general health and social care workforce.

- Prevention of COVID-19 infection: Many people living with dementia had a reduced ability to understand and comply with pandemic restrictions and wearing face masks. LTC facility-related factors were related to COVID-19 outbreaks.

- COVID-19 risk factors in people with dementia included APOE4 homozygosity. Living in a care home and comorbidities increases risk of COVID-19 disease severity.
- Quantitative and longitudinal studies on the impact of COVID-19 and isolation. Studies should be inclusive and assess the impacts of inequalities.

- Impact of restrictions on the wellbeing of care home residents with dementia, care home staff and health and social care professionals who work alongside people with dementia.

- Findings specific to people working with or affected by dementia within broader studies, and dementia-specific findings within care homes with residents who have/do not have dementia should be analysed.

- Monitoring effects of vaccination in people with dementia, as they were not included in published vaccine trials.

- Longitudinal data on the impact of COVID-19 on dementia risk.

\section{Diagnosing well:}

- Reduced access to dementia diagnostic services and reduced diagnosis

- COVID-19 in dementia is often asymptomatic or atypical and may include hypoactive delirium, making accurate PCR testing critical to control spread.

- At the start of the pandemic in some areas, people with dementia in care homes and psychiatric/mental health hospitals were only able to access COVID-19 testing at a later stage compared to others. This likely contributed to local outbreaks.

- Remote assessment and virtual diagnosis of dementia in home-dwelling participants during the pandemic may be feasible. rates during the pandemic.

- Impact of loss of face-to-face assessments and access to diagnostic services during the pandemic on dementia diagnoses and mental health diagnoses in people with dementia.

- Replication of studies conducted during the start of the pandemic at later periods, e.g., subsequent lockdowns, would establish whether lessons were learned and if they (and/or widespread antibody seropositivity) had any impact on infection and mortality rates.

- Optimise remote assessments and ensure those who cannot use or possess the technology are not left behind.

- Studies on post-COVID syndrome ('Long COVID') to include people with dementia to investigate the prevalence and impact of this condition on dementia risk, diagnosis and progression. The potential impact of post-COVID syndrome on carers and the dementia workforce.

- Longitudinal biomarker studies (imaging, fluid, cognitive) to investigate rates of dementia progression following COVID-19.

Treating well:

- Reduced access to and provision of primary care and memory clinic services, alongside an increase in antipsychotic prescribing.

- Responses to telehealth were mixed.

- People with dementia who are hospitalised have specialised needs, but reduced access to health care, which may not be justified.

- Clinical research activities, such as participant recruitment, have been affected.

- Longer-term impact of reduced access to primary and secondary health services.

- The acceptability and effectiveness of telehealth for people living with dementia.

- Factors associated with positive treatment outcomes in people with dementia to inform inappropriate restriction to healthcare and use of DNAR orders.

- Impact of COVID-19 on dementia research, including on existing and future projects, early career researchers, and participant recruitment initiatives.

Supporting well:

- The pandemic has reduced care home residents' and staff wellbeing. Telehealth may benefit some residents.

- Informal or paid home care, day care and other services can mitigate carer stress, but many carers worried about their availability and infection risk and did not access services. Many carers were unable to access remote consultations or support. Financial assistance may be beneficial.

- Reduced access to and use of social care services, e.g. respite care.

- Resources and projects set up or adapted to support national responses to COVID-19.
- Best practice in care homes, relating to visiting, remote communication, infection control whilst reducing loneliness and protecting human rights.

- How to best support dementia care at home, including social, digital, financial and other interventions to reduce carer stress and burden.

- Social care research findings related to older people in particular may be extrapolated to dementia, and specific dementia-related findings should be analysed and reported within broader studies that include these groups. 
BOX 1 (Continued)

Findings from previous/current research

Living well:

- Remote delivery of psychosocial, education and physical interventions have the potential to benefit wellbeing, but the caveats of access to and capacity to use technology also apply.
Directions for future research

- Ongoing and further research to assess the success of remote interventions to improve wellbeing.

- Rehabilitation needs of people affected by dementia, e.g., due to postCOVID syndrome or prolonged isolation.

Dying well:

- Difficult decisions may need to be taken more rapidly in COVID-19, and - Primary research studies on palliative care involving people with decision aids for people with dementia and their families are now available. dementia.

- Studies to help improve advance care planning.

(Long Covid) or experience an exacerbation of other health problems as a result of isolation or reduced access to health and care services.

Dying Well: Ensuring the needs of people with dementia are met at the end of life (Table 7).

We found one published review ${ }^{127}$ but there were no primary research studies on palliative or end of life care relating to COVID-19 and people living with dementia. Studies of palliative care services are underway and are likely to include people living with dementia. The decision-making process in older adults may need to happen more rapidly in the context of COVID-19, ${ }^{128}$ and two ongoing UK studies are developing advance care planning and decision-making tools for people affected by dementia in care homes with nursing (Brazil et al., UKRI, Table 7) and family carers. ${ }^{144}$ UKRI, Table 7). The latter study has produced a freely available evidence-based decision tool to help people with dementia and their family carers make difficult decisions. ${ }^{144}$ Such decisions and consultations are likely to be hampered by the loss of visitor access to many hospitals and care homes during the pandemic, but quantitative research in this area is lacking.

Additional studies as well as the regulator's investigations ${ }^{126}$ on the use of advance decisions to refuse treatments and misuse of DNAR orders may help improve advance care planning for people living with dementia.

\section{4 | DISCUSSION}

Based on the findings that emerged from this initiative, there were directions for future research within each domain that the consensus group considered important (Box 1). Some themes applied across all domains, such as the potential benefits and risks of remote healthcare to deliver interventions and support, the need for longitudinal studies to monitor the longer-term impacts, the risk and impact of widening health and other inequalities, the need for sociodemographically inclusive studies, and the benefit of reporting dementia-specific findings within broader studies.

As this is a fast-moving and rapidly changing area in terms of policies and adaptations, which may outpace the rate of the normal publication process, we have tried to swiftly incorporate research findings from a range of non-peer reviewed sources, including registered systematic reviews in progress, preprint databases and COVID-19-specific websites and reports. This paper presents findings from a literature review and expert consensus, intended to provide comprehensive coverage of several aspects of dementia research related to COVID-19, and was not driven by a specific research question. Our study was not designed to be a traditional systematic or scoping review ${ }^{145}$ and we did not formally quantify the quality of studies. Therefore, our findings may be less comprehensive compared to a protocol-driven search strategy that follows published guidelines and/or systematic critical appraisal.

Members of the consensus group are involved in online projects that can rapidly update evidence relating to COVID-19, for example, the LTCcovid collaboration (www.Itccovid.org). While peer-review remains the gold standard for research publication, databases such as these as well as preprint repositories can provide valuable, timecritical resources during the pandemic.

Another limitation of our study was that some potentially relevant studies of long-term care facilities may have been omitted if they did not explicitly mention inclusion of people with dementia: members of the consensus group identified some such studies, and these are described in the text. Non-specific findings should be interpreted cautiously, including those from large population-based studies/surveys of individuals, families and the health and social care workforce. For example, only $22 \%$ of respondents in the Carers UK survey (Table 2) ${ }^{17}$ were aged over 65 years (an unknown proportion were supporting family members with dementia), thus potentially limiting the generalisability of findings to dementia care.

Other limitations, related to the fast-changing nature of the pandemic, were that the themes and research gaps identified in this study may not apply or become less relevant as the pandemic continues to unfold. At the time of writing, members of the expert consensus were aware that several projects have yet to be announced or have only recently been awarded funding, for example, the NIHR Policy Research Programme (PRP) announced further COVID-19 related studies that may be relevant to dementia in early 2021. These future studies were not detailed in this paper but may fulfil additional themes within the Dementia Wellbeing Pathway or meet identified gaps in research. We structured our findings based on 
the NHS England Dementia Well Pathway, but studies were not conducted with this framework in mind. Thus, research findings may be relevant to more than one domain and the categorisation of studies, by necessity, may sometimes have been imprecise. As this study was prompted by a question from the English Dementia Programme Board on research on dementia and COVID-19, and our consensus group were English-based experts, our findings and consensus views were skewed towards research based in England.

Overall, the COVID-19 pandemic has had a disproportionately negative impact on dementia wellbeing, and researchers and funding organisations have responded rapidly to try to understand the impacts. We have identified potential directions for future research to explore these further, so that evidence-based measures can be developed to improve the quality of life of people affected by dementia.

\section{ACKNOWLEDGEMENTS}

Jemma Kehoe (NHS England and NHS Improvement), Robyn Polisano (Department of Health and Social Care) and John Wilkinson (Department of Health and Social Care) were involved in the initial group discussion. $\mathrm{KL}$ is supported by the Medical Research Council (MR/S021418/1), RH, GL and AS are supported by the UCLH NIHR Biomedical Research Centre, SB is supported by grants from the Economic and Social Research Council (ESRC), EPSRC, and NIHR, AC is supported by the UK Research and Innovation Global Challenges Research Fund (ES/P010938/1), GL is supported by North Thames NIHR ARC, JM is supported by NIHR Policy Research Programme and NIHR ARC South London, RWP is supported by the UCLH Queen Square NIHR biomedical research centre, an Alzheimer's Association Clinicians Scientist fellowship and the UK Dementia Research Institute. JBR is supported by the Cambridge NIHR Biomedical Research Centre (BRC-1215-20,014) and Medical Research Council (SUAG/ 051 G101400). ASG is supported by the RDS Impact study (ES/ S010467/1), funded jointly by the ESRC and the NIHR. The views expressed are those of the authors and not necessarily those of the NHS, the National Institute for Health Research (NIHR), or the Department of Health and Social Care.

\section{CONFLICT OF INTEREST}

None.

\section{DATA AVAILABILITY STATEMENT}

Data sharing not applicable to this article as no additional datasets were generated or analysed during the current study.

\section{ORCID}

Kathy Y. Liu (D) https://orcid.org/0000-0002-7482-2758

Louise Robinson (D) https://orcid.org/0000-0003-0209-2503

Alistair Burns (D) https://orcid.org/0000-0002-9837-0645

\section{REFERENCES}

1. Atkins JL, Masoli JAH, Delgado J, et al. Preexisting comorbidities predicting COVID-19 and mortality in the UK biobank community cohort. J Gerontol A Biol Sci Med Sci. 2020;75(11):2224-2230.
2. Liu N, Sun J, Wang $X$, Zhao $M$, Huang Q, Li H. The impact of dementia on the clinical outcome of COVID-19: a systematic review and meta-analysis. J Alzhimer Dis. 2020;78(4):1775-1782.

3. Suárez-González A, Livingston G, Lee-Fay-Low, et al. Impact and mortality of COVID-19 on people living with dementia: crosscountry report. 2020. https://ltccovid.org/2020/08/19/impactand-mortality-of-covid-19-on-people-living-with-dementia-crosscountry-report/. Accessed 4 January 2021.

4. Alzheimer's Society. Worse hit: dementia during coronavirus; 2020. https://www.alzheimers.org.uk/sites/default/files/2020-09/ Worst-hit-Dementia-during-coronavirus-report.pdf.

5. Dementia UK. 2020. Facing it alone. https://www.dementiauk.org/ wp-content/uploads/2020/11/Facing-It-Alone.pdf

6. Public Health England. 2020. Disparities in the risk and outcomes of COVID-19. https://assets.publishing.service.gov.uk/ government/uploads/system/uploads/attachment_data/file/ 908434/Disparities in the risk_and_outcomes_of_COVID_August 2020_update.pdf

7. NHS England. Dementia wellbeing in the COVID-19 pandemic. 2020. https://www.england.nhs.uk/publication/dementiawellbeing-in-the-covid-19-pandemic/. Accessed December 1, 2020.

8. NHS England. 2016. Dementia well pathway. https://www.england. nhs.uk/mentalhealth/wp-content/uploads/sites/29/2016/03/ dementia-well-pathway.pdf

9. Department of Health. 2016. Prime minister's challenge on dementia 2020 implementation plan. https://assets.publishing. service.gov.uk/government/uploads/system/uploads/attachment data/file/507981/PM_Dementia-main_acc.pdf

10. LTC Covid projects. Research Projects on COVID-19 and LongTerm Care. LTCcovid; 2020. https://ltccovid.org/completed-orongoing-research-projects-on-covid-19-and-long-term-care/? groups=people-with-dementia. Accessed December 14, 2020.

11. UKRI. COVID-19 research and innovation supported by UKRI; 2020. https://www.ukri.org/find-covid-19-research-andinnovation-supported-by-ukri/. Accessed January 6, 2021.

12. NIHR. Funding and awards. NIHR. 2020a. https://fundingawards. nihr.ac.uk/search. Accessed December 14, 2020.

13. Moher D, Liberati A, Tetzlaff J, Altman DG, PRISMA Group. 2009 Preferred reporting items for systematic reviews and meta-analyses: the PRISMA statement. PLoS Med. 6(7):e1000097.

14. Lithgow $S$, Jackson GA, Browne D. Estimating the prevalence of dementia: cognitive screening in Glasgow nursing homes. Int $J$ Geriatr Psychiatr. 2012;27(8):785-791.

15. Livingston G, Barber J, Marston L, et al. Prevalence of and associations with agitation in residents with dementia living in care homes: MARQUE cross-sectional study. BJPsych Open. 2017;3(4) 171-178.

16. Age UK. 2020. The impact of COVID-19 to date on older people's mental and physical health. Age UK. https://www.ageuk.org.uk/ globalassets/age-uk/documents/reports-and-publications/reportsand-briefings/health--wellbeing/the-impact-of-covid-19-onolder-people_age-uk.pdf. Accessed 4 January 2021.

17. Carers UK. 2020. Caring behind closed doors. https://www. carersuk.org/images/News_and_campaigns/Behind_Closed_Doors_ 2020/Caring_behind_closed_doors_April20_pages_web_final.pdf

18. Suarez-Gonzalez A, Livingston G, Comas-Herrera A. Updated Report the impact of the COVID-19 pandemic on people living with dementia in UK. 2020. https://tccovid.org/2020/06/01/updated-report-theimpact-of-the-covid-19-pandemic-on-people-living-with-dementiain-uk/. Accessed 4 January 2021

19. van Maurik IS, Bakker ED, van den Buuse S, et al. Psychosocial effects of corona measures on patients with dementia, mild cognitive impairment and subjective cognitive decline. Front Psychiatr. 2020;11:585686. 
20. Palermo G, Tommasini L, Baldacci F, Del Prete E, Siciliano G, Ceravolo R. Impact of coronavirus disease 2019 pandemic on cognition in Parkinson's disease. Mov Disord. 2020;35(10): 1717-1718.

21. Di Santo SG, Franchini F, Filiputti B, Martone A, Sannino S. The effects of COVID-19 and quarantine measures on the lifestyles and mental health of people over 60 at increased risk of dementia. Front Psychiatr. 2020;11:578628.

22. Manca R, De Marco M, Venneri A. The impact of COVID-19 infection and enforced prolonged social isolation on neuropsychiatric symptoms in older adults with and without dementia: a review. Front Psychiatr. 2020;11:585540.

23. Tsapanou A, Papatriantafyllou JD, Yiannopoulou K, et al. The impact of COVID-19 pandemic on people with mild cognitive impairment/dementia and on their caregivers. Int J Geriatr Psychiatr. 2020;36:583-587. https://doi.org/10.1002/gps.5457

24. Lara B, Carnes A, Dakterzada F, Benitez I, Piñol-Ripoll G. Neuropsychiatric symptoms and quality of life in Spanish patients with Alzheimer's disease during the COVID-19 lockdown. Eur J Neurol. 2020;27(9):1744-1747.

25. Goodman-Casanova JM, Dura-Perez E, Guzman-Parra J, CuestaVargas A, Mayoral-Cleries F. Telehealth home support during COVID-19 confinement for community-dwelling older adults with mild cognitive impairment or mild dementia: survey study. J Med Internet Res. 2020;22(5):e19434.

26. O'Caoimh R, O'Donovan MR, Monahan MP, et al. Psychosocial impact of COVID-19 nursing home restrictions on visitors of residents with cognitive impairment: a cross-sectional study as part of the engaging remotely in care (ERiC) project. Front Psychiatr. 2020;11:585373.

27. Nyashanu M, Pfende F, Ekpenyong MS. Triggers of Mental Health Problems among Frontline Healthcare Workers during the COVID-19 Pandemic in Private care Homes and Domiciliary care agencies: Lived Experiences of Care Workers in the Midlands region, UK: Health Soc Care Community. 2020. https://doi.org/10.1111/hsc.13204

28. Cohen G, Russo MJ, Campos JA, Allegri RF. COVID-19 epidemic in Argentina: worsening of behavioral symptoms in elderly subjects with dementia living in the community. Front Psychiatr. 2020;11:866.

29. Cagnin A, Di Lorenzo R, Marra C, et al. Behavioral and psychological effects of coronavirus disease-19 quarantine in patients with dementia. Front Psychiatr. 2020;11:578015.

30. Boutoleau-Bretonnière $\mathrm{C}$, Pouclet-Courtemanche $\mathrm{H}$, Gillet $\mathrm{A}$, et al. The effects of confinement on neuropsychiatric symptoms in alzheimer's disease during the COVID-19 crisis. J Alzhimer Dis. 2020;76(1):41-47.

31. El Haj M, Altintas E, Chapelet G, Kapogiannis D, Gallouj K. High depression and anxiety in people with Alzheimer's disease living in retirement homes during the covid-19 crisis. Psychiatr Res 2020;291:113294.

32. Carpinelli Mazzi M, lavarone A, Musella C, et al. Time of isolation, education and gender influence the psychological outcome during COVID-19 lockdown in caregivers of patients with dementia. Eur Geriatr Med. 2020;11(6):1095-1098.

33. Altieri M, Santangelo G. The psychological impact of COVID-19 pandemic and lockdown on caregivers of people with dementia. Am J Geriatric Psychiatry. 2021;29:27-34. https://doi.org/10.1016/j. jagp.2020.10.009

34. Alexopoulos P, Soldatos R, Kontogianni E, et al. COVID-19 crisis effects on caregiver distress in neurocognitive disorder. J Alzheimer's Dis. 2021;79:459-466. https://doi.org/10.3233/JAD-200991

35. Borges-Machado F, Barros D, Ribeiro Ó, Carvalho J. The effects of COVID-19 home confinement in dementia care: physical and cognitive decline, severe neuropsychiatric symptoms and increased caregiving burden. Am J Alzheimers Dis Other Demen. 2020;35: 1533317520976720.

36. Penteado CT, Loureiro JC, Pais MV, et al. Mental health status of psychogeriatric patients during the 2019 new coronavirus disease (COVID-19) pandemic and effects on caregiver burden. Front Psychiatr. 2020;11:578672.

37. Soldevila-Domenech N, Forcano L, Boronat A, et al. Effects of COVID-19 home confinement on mental health in individuals with increased risk of alzheimer's disease. J Alzhimer Dis. 2021;79:1015-1021. https://doi.org/10.3233/JAD-201408

38. Roach P, Zwiers A, Cox E, et al. Understanding the impact of the COVID-19 pandemic on well-being and virtual care for people living with dementia and care partners living in the community. Dementia. 2020:1471301220977639.

39. Thyrian JR, Kracht F, Nikelski A, et al. The situation of elderly with cognitive impairment living at home during lockdown in the Corona-pandemic in Germany. Research Square. 2020. https://doi. org/10.21203/rs.3.rs-38185/v1

40. Baschi R, Luca A, Nicoletti A, et al. Changes in motor, cognitive, and behavioral symptoms in Parkinson's disease and mild cognitive impairment during the COVID-19 lockdown. Front Psychiatr. 2020;11:590134.

41. Koh ZY, Law F, Chew J, Ali N, Lim WS. Impact of coronavirus disease on persons with dementia and their caregivers: an audit study. Ann Geriatr Med Res. 2020;24(4):316-320.

42. Barguilla A, Fernández-Lebrero A, Estragués-Gázquez I, et al. Effects of COVID-19 pandemic confinement in patients with cognitive impairment. Front Neurol. 2020;11:589901.

43. Iodice F, Cassano V, Rossini PM. Direct and indirect neurological, cognitive, and behavioral effects of COVID-19 on the healthy elderly, mild-cognitive-impairment, and Alzheimer's disease populations. Neurol Sci. 2021;42:455-465. https://doi.org/10.1007/ s10072-020-04902-8

44. Jeon $\mathrm{Y}-\mathrm{H}$, Shin M, Waters D, et al. 2020. Impact of COVID-19 public health measures on the life and wellbeing and access to care and support of people living with dementia and care partners in Australia. https://www.dementia.org.au/sites/default/files/2020-11/PFODDiscussion-Paper-Nov-2020-ver1.pdf

45. Porcari DE, Palmer K, Spalletta G, Ciullo V, Banaj N. A survey for examining the effects of COVID-19 and infection control measures in older persons with mild cognitive impairment and dementia and their caregivers. Front Psychiatr. 2020;11:599851.

46. Daley S, Farina N, Hughes L, et al. How has COVID 19 affected the quality of life, wellbeing, and care of people diagnosed with dementia and their family carers? A nested Time for Dementia sub study. 2021. https:// Itccovid.org/project/how-has-covid-19-affected-the-quality-oflife-wellbeing-and-care-of-people-diagnosed-with-dementia-andtheir-family-carers-a-nested-time-for-dementia-sub-study/. Accessed 14 May 2021.

47. Suarez-Gonzalez A, Rajagopalan J, Alladi S. The impact of Covid-19 confinement and isolation measures on people with dementia: a rapid review. 2021. https://Itccovid.org/project/the-impact-of-covid-19confinement-and-isolation-measures-on-people-with-dementia-arapid-review/. Accessed 14 May 2021.

48. Stockwell S, Trott M, Smith L, Tully M. Physical activity and sedentary behaviours of people during the COVID-19 pandemic lockdown compared with before the lockdown. 2021. https://www.crd.york.ac. uk/prospero/display_record.php?RecordID $=193065$ Accessed January 8, 2021.

49. Lorenz-Dant K, Comas-Herrera A. Pre-print: The impacts of COVID19 on unpaid carers of adults with long-term care needs and measures to address these impacts: a rapid review of the available evidence. 2021. https://ltccovid.org/2021/01/15/pre-print-the-impacts-ofcovid-19-on-unpaid-carers-of-adults-with-long-term-care-needs- 
and-measures-to-address-these-impacts-a-rapid-review-of-the-avail able-evidence/. Accessed 15 January 2021.

50. Kobayashi R, Hayashi H, Kawakatsu S, et al. Recognition of the coronavirus disease 2019 pandemic and face mask wearing in patients with Alzheimer's disease: an investigation at a medical centre for dementia in Japan. Psychogeriatrics. 2020;20(6):923-925.

51. Suzuki $M$, Hotta $M$, Nagase $A$, et al. The behavioral pattern of patients with frontotemporal dementia during the COVID-19 pandemic. Int Psychogeriatr. 2020;32(10):1231-1234.

52. Tsugawa A, Sakurai S, Inagawa Y, et al. Awareness of the COVID19 outbreak and resultant depressive tendencies in patients with severe alzheimer's disease. J Alzhimer Dis. 2020;77(2):539-541.

53. Hashimoto $M$, Suzuki $M$, Hotta $M$, et al. The influence of the COVID-19 outbreak on the lifestyle of older patients with dementia or mild cognitive impairment who live alone. Front Psychiatr. 2020;11:570580.

54. Kuo C-L, Pilling LC, Atkins JL, et al. APOE e4 Genotype Predicts Severe COVID-19 in the UK Biobank Community Cohort. J Gerontol A Biol Sci Med Sci. 2020;75(11):2231-2232.

55. Sainz-Amo R, Baena-Álvarez B, Pareés I, et al. COVID-19 in Parkinson's disease: what holds the key? J Neurol. 2020. https://doi. org/10.1007/s00415-020-10272-0

56. De Smet R, Mellaerts B, Vandewinckele H, et al. Frailty and mortality in hospitalized older adults with COVID-19: retrospective observational study. J Am Med Dir Assoc. 2020;21:928-932. Cold Spring Harbor Laboratory Press. https://doi.org/10.1016/j.jamda. 2020.06.008

57. Li J, Li Y, Li Z, Liu Y. The frailty assessment as a predictor of mortality and adverse outcomes in patients with COVID-19: a systematic review. 2021. https://www.crd.york.ac.uk/prospero/display_record.php? RecordID=189132. Accessed January 8, 2021.

58. Dutey-Magni PF, Williams $\mathrm{H}$, Jhass A, et al. COVID-19 infection and attributable mortality in UK care homes: cohort study using active surveillance and electronic records (March-June 2020). Cold Spring Harbor Laboratory Press; 2020. medRxiv. https://doi.org/10.1101/ 2020.07.14.20152629

59. Brown KA, Jones A, Daneman N, et al. Association between nursing home crowding and COVID-19 infection and mortality in Ontario, Canada. JAMA Intern Med. 2021;181:229. https://doi.org/10.1001/ jamainternmed.2020.6466

60. Frazer K, Mitchell L, Stokes D, Lacey E, Crowley E, Kelleher C. A rapid systematic review of measures to protect older people in long term care facilities from COVID-19. Public and Global Health. 2020. medRxiv. https://doi.org/10.1101/2020.10.29.20222182

61. Nizama-Vía A, Alonso-Sánchez A, Serra-Mestres J. Experience of an acute old age psychiatric ward in the early stages of the coronavirus disease 2019 pandemic in the UK. Psychogeriatrics. 2020;20(6):920-922.

62. Bianchetti A, Rozzini R, Guerini F, et al. Clinical presentation of COVID19 in dementia patients. J Nutr Health Aging. 2020;24(6): 560-562.

63. Louie JK, Scott HM, Lu W, et al. COVID-19-Associated deaths in san francisco: the important role of dementia and atypical presentations in long-term care facilities. J Gen Intern Med. 2020;35: 3413-3415.

64. Rebora P, Rozzini R, Bianchetti A, et al. Delirium in patients with SARS-CoV -2 infection: a multicenter study. J Am Geriatr Soc. 2020;69:293-299. https://doi.org/10.1111/jgs.16969

65. Canevelli M, Palmieri L, Raparelli V, et al. Prevalence and clinical correlates of dementia among COVID-19-related deaths in Italy. Alzheimers Dement. 2020;12(1):e12114.

66. Rutten JJS, van Loon AM, van Kooten J, et al. Clinical suspicion of COVID-19 in nursing home residents: symptoms and mortality risk factors. J Am Med Dir Assoc. 2020;21(12):1791-1797.
67. Livingston G, Rostamipour H, Gallagher P, et al. Prevalence, management, and outcomes of SARS-CoV-2 infections in older people and those with dementia in mental health wards in London, UK: a retrospective observational study. Lancet Psychiatry. 2020;7(12): 1054-1063.

68. Graham NSN, Junghans C, Downes R, et al. SARS-CoV-2 infection, clinical features and outcome of COVID-19 in United Kingdom nursing homes. J Infect. 2020;81(3):411-419.

69. Pranata R, Lim M, Huang I, Vania R. Delirium and Mortality in Coronavirus Disease 2019 (COVID-19) - A Systematic Review and Meta-Analysis; 2021. https://www.crd.york.ac.uk/prospero/display_ record.php?RecordID=223351. Accessed January 8, 2021.

70. Weiss EF, Malik R, Santos T, et al. Telehealth for the cognitively impaired older adult and their caregivers: lessons from a coordinated approach. Neurodegener Dis Manag. 2021;11:83-89. https:// doi.org/10.2217/nmt-2020-0041

71. Capozzo R, Zoccolella S, Frisullo ME, et al. Telemedicine for delivery of care in frontotemporal lobar degeneration during COVID19 pandemic: results from southern Italy. J Alzheimers Dis. 2020;76(2):481-489.

72. Owens AP, Ballard C, Beigi M, et al. Implementing remote memory clinics to enhance clinical care during and after COVID-19. Front Psychiatr. 2020;11:579934.

73. Geddes MR, O'Connell ME, Fisk JD, et al. Remote cognitive and behavioral assessment: report of the Alzheimer Society of Canada Task Force on dementia care best practices for COVID-19. Alzheimer's \& Dementia: Diagnosis. Assessment \& Disease Monitoring. 2020;12(1):1.

74. Carlew AR, Fatima H, Livingstone JR, et al. Cognitive assessment via telephone: a scoping review of instruments. Arch Clin Neuropsychol. 2020;35(8):1215-1233.

75. Domingues RB, Mantese CE, Aquino EdS, Fantini FGMM, Prado GFd, Nitrini R. Telemedicine in neurology: current evidence. Arq Neuro Psiquiatr. 2020;78(12):818-826.

76. NHS England. Memory Service Assessments: A New Way of Working; 2020. http://www.yhscn.nhs.uk/media/PDFs/mhdn/Dementia/ Covid\%2019/MAS/2020\%2005\%2027\%20MSA\%20-\%20A\% 20New\%20Way\%20of\%20Working\%20-\%20Remote\%20Memory \%20Clinics\%20FINAL.pdf. Accessed April 25, 2021.

77. Michalowsky B, Hoffmann W, Bohlken J, Kostev K. Effect of the COVID-19 lockdown on disease recognition and utilisation of healthcare services in the older population in Germany: a crosssectional study. Age Ageing. 2020;50:317-325. https://doi.org/10. 1093/ageing/afaa260

78. Chen S, She R, Qin P, et al. The medium-term impact of COVID-19 lockdown on referrals to secondary care mental health services: a controlled interrupted time series study. Front Psychiatr. 2020;11: 585915.

79. Spalletta G, Porcari DE, Banaj N, Ciullo V, Palmer K. Effects of COVID-19 infection control measures on appointment cancelation in an Italian outpatient memory clinic. Front Psychiatr. 2020;11: 599844.

80. Ousset PJ, Vellas B. Viewpoint: impact of the covid-19 outbreak on the clinical and research activities of memory clinics: an Alzheimer's disease center facing the covid-19 crisis. J Prev Alzheimers Dis. 2020;7(3):197-198.

81. Benaque A, Gurruchaga MJ, Abdelnour C, et al. Dementia care in times of COVID-19: experience at fundació ACE in Barcelona, Spain. J Alzhimer Dis. 2020;76(1):33-40.

82. Schilling S, Mohanarajah S, Mengstu A, Khan A, Brown WA. How a psychopharmacology clinical trial site in the seattle area managed clinical trials and patient care during the COVID-19 pandemic. Am J Geriatric Psychiatry. 2020;28(9): 999-1003. 
83. Abdelnour C, Esteban de Antonio E, Pérez-Cordón A, et al. Managing clinical trials for alzheimer's disease during the COVID-19 crisis: experience at fundació ACE in Barcelona, Spain. J Alzheimer's Dis. 2020;77(4):1805-1813.

84. Di Lorito C, Bosco A, Goldberg SE, et al. Protocol for the process evaluation of the promoting activity, independence and stability in early dementia (PrAISED), following changes required by the COVID-19 pandemic. BMJ Open. 2020;10(8):e039305.

85. Schwab NA, DesRuisseaux LA, Weinberg MS, Arnold SE. Saving cognitive outcome data in Alzheimer's disease clinical trials during the COVID-19 pandemic: commentary on the virtual administration of the ADAS-Cog. Alzheimers Dement. 2020;6(1): e12081.

86. Abate F, Erro R, Barone P, Picillo M. Managing device-aided treatments in Parkinson's disease in times of COVID-19. Mov Disord Clin Pract. 2020;7(6):737-738.

87. Bhome R, Huntley J, Dalton- Locke C, et al. Impact of the COVID19 pandemic on older adults mental health services: a mixed methods study. Biorxiv. medRxiv. 2020. https://doi.org/10.1101/ 2020.11.14.20231704

88. Tuijt R, Rait G, Frost R, Wilcock J, Manthorpe J, Walters K. Remote primary care consultations for people living with dementia during the COVID-19 pandemic: experiences of people living with dementia and their carers. Br J Gen Pract. 2021. BJGP.2020.1094. https://doi.org/10.3399/BJGP.2020.1094

89. Steare T, Wood L, Goulding L, et al. Remote working in mental health services: a rapid umbrella review of pre-COVID-19 literature. 2021. https://www.crd.york.ac.uk/prospero/display_record.php? RecordID=208085. Accessed January 8, 2021.

90. Ty ML, Espiritu A, Leochico C, Turalde CW. Meta-analysis and systematic review on patient satisfaction in teleneurology. 2021. https://www.crd.york.ac.uk/prospero/display_record.php?Record ID =190626. Accessed January 8, 2021.

91. Kerslake R, Cherry S, Buckle J, Harris R, Caplan R. Clinical course of 12 patients on a Covid-19 dementia isolation ward. BJPsych Bull. 2020;44(6):288-290.

92. Li J, Long $\mathrm{X}$, Huang $\mathrm{H}$, et al. Resilience of alzheimer's disease to COVID-19. J Alzhimer Dis. 2020;77(1):67-73.

93. Gómez-Ramiro M, Fico G, Anmella G, et al. Changing trends in psychiatric emergency service admissions during the COVID-19 outbreak: report from a worldwide epicentre. J Affect Disord. 2020;282:26-32.

94. Shea YF, Shum CK, Wan WH, Chan MMK. Worsening behavioural and psychological symptoms of dementia during the coronavirus disease 2019 pandemic. Psychogeriatrics. 2020;20(6):916-917.

95. Simonetti A, Pais C, Jones $\mathrm{M}$, et al. Neuropsychiatric symptoms in elderly with dementia during COVID-19 pandemic: definition, treatment, and future directions. Front Psychiatr. 2020;11:579842.

96. Howard R, Burns A, Schneider L. Antipsychotic prescribing to people with dementia during COVID-19. Lancet Neurol 2020; 19(11):892.

97. Stall NM, Zipursky JS, Rangrej J, et al. Increased prescribing of psychotropic medications to Ontario nursing home residents during the COVID-19 pandemic. bioRxiv. medRxiv. 2020. https://doi. org/10.1101/2020.11.26.20239525

98. Verbeek H, Gerritsen DL, Backhaus R, de Boer BS, Koopmans RTCM, Hamers JPH. Allowing visitors back in the nursing home during the COVID-19 crisis: a Dutch national study into first experiences and impact on well-being. J Am Med Dir Assoc. 2020;21(7):900-904

99. Shum CK, Shea YF, Tang M, Wan WH, Chan MMK. Poor feeding due to visitor restrictions in long-term care facilities during the coronavirus disease 2019 pandemic. Psychogeriatrics. 2020;20(6): 929-930.
100. Lombardo FL, Salvi E, Lacorte E, et al. Adverse events in Italian nursing homes during the COVID-19 epidemic: a national survey. Front Psychiatr. 2020;11:578465.

101. Leontjevas R, Knippenberg IAH, Smalbrugge $M$, et al. Challenging behavior of nursing home residents during COVID-19 measures in The Netherlands. Aging Ment Health. 2020:1-6.

102. Surr C, Kelley R, Griffiths A, et al. Identifying approaches, barriers and facilitators to visiting in care homes during the COVID-19 pandemic. 2021. https://enrich.nihr.ac.uk/blogpost/identifying-approachesbarriers-and-facilitators-to-visiting-in-care-homes-during-the-covid19-pandemic/. Accessed 14 May 2021.

103. Fitzpatrick J. Protecting older people living in care homes from COVID-19: challenges and solutions to implementing bookdistancing and isolation. NIHR Funding and Awards. 2021. https://www. fundingawards.nihr.ac.uk/award/NIHR132541. Accessed 4 January 2021.

104. Vaitheswaran S, Lakshminarayanan M, Ramanujam V, Sargunan S, Venkatesan S. Experiences and needs of caregivers of persons with dementia in India during the COVID-19 pandemic-A qualitative study. Am J Geriatric Psychiatry. 2020;28(11):1185-1194.

105. Sorbara M, Graviotto HG, Lage-Ruiz GM, et al. COVID-19 y la pandemia olvidada: el seguimiento de las enfermedades neurocognitivas durante la cuarentena en Argentina. Neurologia. 2021;36:9-15. https://doi.org/10.1016/j.nrl.2020.07.015

106. Monin JK, Ali T, Syed S, et al. Family communication in long-term care during a pandemic: lessons for enhancing emotional experiences. Am J Geriatric Psychiatry. 2020;28(12):1299-1307.

107. Zamir S, Hennessy C, Taylor A, Jones R. Intergroup 'skype' quiz sessions in care homes to reduce loneliness and social isolation in older people. Geriatrics. 2020;5(4):90. Multidisciplinary Digital Publishing Institute.

108. Lai FH-y, Yan EW-h, Yu KK-y, Tsui W-S, Chan DT-h, Yee BK. The protective impact of telemedicine on persons with dementia and their caregivers during the COVID-19 pandemic. Am J Geriatric Psychiatry. 2020;28(11):1175-1184.

109. Windle G, Stott J, Spector A, et al. A randomised controlled trial and feasibility study of the effects of an e-health intervention "iSupport" for reducing distress of dementia carers, especially in the ongoing pandemic of COVID-19. 2023. https://www.fundingawards.nihr.ac.uk/award/ NIHR130914. Accessed 14 May 2021

110. Savla J, Roberto KA, Blieszner R, McCann BR, Hoyt E, Knight AL. Dementia caregiving during the "stay-at-home" phase of COVID19 pandemic. J Gerontol B Psychol Sci Soc Sci. 2020;76:e241-e245. https://doi.org/10.1093/geronb/gbaa129

111. Giebel C, Cannon J, Hanna K, et al. Impact of COVID-19 related social support service closures on people with dementia and unpaid carers: a qualitative study. Aging Ment Health. 2020:1-8. https://doi.org/10.1080/13607863.2020.1822292

112. Geyer J, Böhm F, Müller J, et al. Die Lebenssituation von Menschen mit Demenz und pflegenden Angehörigen während der CoronavirusPandemie Eine qualitative Studie. Pflege. 2020;33(4):189-197.

113. Cohen G, Russo MJ, Campos JA, Allegri RF. Living with dementia: increased level of caregiver stress in times of COVID-19. Int Psychogeriatr. 2020;32(11):1377-1381.

114. Egunsola O, Mastikhina L, Lorenzetti D, et al. Rapid Review of Best Practices for Care and Engagement for Persons with Cognitive Impairments during the COVID19 Pandemic. Health Technology Assessment Unit, University of Calgary; 2020. https://obrieniph.ucalgary. ca/sites/default/files/teams/5/FINAL\%20Rapid\%20reviews.pdf

115. Dowsett L, Egunsola O, Mastikhina L, Clement F. 2020. A rapid review of best practices for isolation and quarantine due to Covid-19 on individuals with cognitive impairment. https://www.crd.york.ac.uk/ prospero/display_record.php?RecordID $=210905$. Accessed 14 May 2021. 
116. Brotherhood EV, Stott J, Windle G, et al. Protocol for the rare dementia support impact study: RDS impact. Int J Geriatr Psychiatry. 2020;35(8):833-841.

117. Giebel C, Lord K, Cooper C, et al. A UK survey of COVID-19 related social support closures and their effects on older people, people with dementia, and carers. Int J Geriatr Psychiatr. 2020;36:393-402. https://doi.org/10.1002/gps.5434

118. Berridge C, Parsey CM, Ramirez M, Freitag C, Johnson IM, Allard SW. Caring for Washington's Older Adults in the COVID-19 Pandemic: Interviews with Organization Leaders about the State of Social and Healthcare Services; 2020. https://digital.lib.washington. edu/researchworks/bitstream/handle/1773/46272/CARING\%20 FOR\%20WASHINGTON\%e2\%80\%99S\%20OLDER\%20ADULTS\% 20IN\%20THE\%20COVID-19\%2OPANDEMIC\%20-\%20Clara\%20 W\%20Berridge.pdf?sequence $=1$ \&isAllowed $=\mathrm{y}$

119. Samsi K, Manthorpe J, Cole L, Orellana K Taking a break: Use of residential respite by people with dementia and carers: experiences, access, outcomes. 2021. https://www.alzheimers.org.uk/ research/our-research/research-projects/residential-respite-careexperiences-access-and-outcomes. Accessed January 5, 2021.

120. STRiDE. Research on COVID-19. STRiDE; 2020. https://stridedementia.org/research/research-on-covid-19/ Accessed January 4, 2021.

121. Vedel I. Improving the care of older adults living with dementia across Canada during the COVID pandemic: a mixed methods study to inform policy and practice. 2021. https://www.mcgill.ca/ familymed/research/projects/research-organization-healthcareservices-alzheimers-rosa/our-team. Accessed January 8, 2021.

122. Quinn L, Macpherson C, Long K, Shah H. Promoting physical activity via telehealth in people with Parkinson disease: the path forward after the COVID-19 pandemic? Phys Ther. 2020;100(10):1730-1736.

123. Alves GS, Casali ME, Veras AB, et al. A systematic review of homesetting psychoeducation interventions for behavioral changes in dementia: some lessons for the COVID-19 pandemic and postpandemic assistance. Front Psychiatr. 2020;11:577871.

124. Fernández-Ruiz VE, Paredes-lbáñez R, Armero-Barranco D, Sánchez-Romera JF, Ferrer M. Analysis of quality of life and nutritional status in elderly patients with dysphagia in order to prevent hospital admissions in a COVID-19 pandemic. Life. 2020;11(1):22. https://doi.org/10.3390/life11010022

125. Cousins E, de Vries K, Dening KH. Ethical care during COVID-19 for care home residents with dementia. Nursing Ethics. 2021;28(1):46-57. https://doi.org/10.1177/0969733020976194

126. Care Quality Commission. Protect, respect, connect - decisions about living and dying well during COVID-19. 2021. https://www. cqc.org.uk/sites/default/files/20210318_dnacpr_printer-version. pdf. Accessed April 25, 2021.

127. Bolt SR, van der Steen JT, Mujezinović I, et al. Practical nursing recommendations for palliative care for people with dementia living in long-term care facilities during the COVID-19 pandemic: a rapid scoping review. Int J Nurs Stud. 2020;113:103781.

128. West E, Moore K, Kupeli N, et al. Rapid review of decision-making for place of care and death in older people: lessons for COVID-19. Age Ageing. 2020;50:294-306. https://doi.org/10.1093/ageing/ afaa289

129. Suárez-González A, Harding E, Zimmerman N, Hoare Z, Brotherhood E, Crutch S. The impact of the first UK Covid-19 lockdown on carers and people living with low prevalence dementia: results from the Rare Dementia Support survey. bioRxiv. medRxiv. 2020. https://doi.org/10.1101/2020.12.18. 20248455

130. Voysey M, Clemens SAC, Madhi SA, et al. Safety and efficacy of the ChAdOx1 nCoV-19 vaccine (AZD1222) against SARS-CoV-2: an interim analysis of four randomised controlled trials in Brazil, South Africa, and the UK. Lancet. 2020;397:99-111. https://doi. org/10.1016/S0140-6736(20)32661-1
131. Witham MD, Anderson E, Carroll CB, et al. Ensuring that COVID19 research is inclusive: guidance from the NIHR INCLUDE project. BMJ Open. 2020;10(11):e043634.

132. Ibanez A, Kosik KS. Latin America and the Caribbean Consortium on Dementia (LAC-CD). 2020. COVID-19 in older people with cognitive impairment in Latin America. Lancet Neurology. 2020;19(9):719-721.

133. NHS Digital. Recorded dementia diagnoses - NHS digital. 2020. https://digital.nhs.uk/data-and-information/publications/statistical /recorded-dementia-diagnoses/. Accessed 5 January 2021.

134. NHS Digital. Dementia: 65+ estimated diagnosis rate - NHS digital. 2019. https://digital.nhs.uk/data-and-information/nationalindicator-library/dementia-65-estimated-diagnosis-rate. Accessed 5 January 2021.

135. Capozzo R, Zoccolella S, Musio M, Barone R, Accogli M, Logroscino G. Telemedicine is a useful tool to deliver care to patients with amyotrophic lateral sclerosis during COVID-19 pandemic: results from Southern Italy. Amyotroph Lateral Scler Frontotemporal Degener. 2020;21(7-8):542-548.

136. Del Rio C, Collins LF, Malani P. Long-term health consequences of COVID-19. J Am Med Assoc. 2020;324:1723. https://doi.org/10. 1001/jama.2020.19719

137. Mahase E. Covid-19: what do we know about 'long covid'? BMJ. 2020;370:m2815.

138. Davis HE, Assaf GS, McCorkell L, et al. Characterizing long COVID in an international cohort: 7 months of symptoms and their impact. bioRxiv. 2020. medRxiv https://doi.org/10.1101/2020.12.24. 20248802

139. NIHR. Research into the longer term effects of COVID-19 in nonhospitalised individuals - call scope. 2020b. https://www.nihr.ac.uk/ documents/research-into-the-longer-term-effects-of-covid-19-innon-hospitalised-individuals-call-scope/26101. Accessed January 4, 2021.

140. Serrano-Castro PJ, Estivill-Torrús G, Cabezudo-García P, et al. Impact of SARS-CoV-2 infection on neurodegenerative and neuropsychiatric diseases: a delayed pandemic? Neurol Engl Ed. 2020;35(4):245-251.

141. Schindler SE, Jicha GA, Nelson PT, et al. Maximizing safety in the conduct of alzheimer's disease fluid biomarker research in the era of COVID-19. J Alzhimer Dis. 2020;76(1):27-31.

142. Giebel C, Hanna K, Cannon J, et al. Decision-making for receiving paid home care for dementia in the time of COVID-19: a qualitative study. BMC Geriatr. 2020;20(1):333.

143. Tuijt R. How has healthcare changed for people with dementia during the pandemic? Alzheimer's Society funded PriDem project. 2020. https://www.alzheimers.org.uk/blog/researchers-supporting-fightagainst-coronavirus. Accessed January 4, 2021.

144. Davies N, Kupeli N, Sampson E. et al. 2020. Decision aid. https:// www.ucl.ac.uk/psychiatry/sites/psychiatry/files/endemic_decision_ aid_26_08_20_v.2.pdf

145. Aromataris E, Munn Z. JBI manual for evidence synthesis. JBI. 2020. https://doi.org/10.46658/JBIMES-20-01

\section{SUPPORTING INFORMATION}

Additional supporting information may be found online in the Supporting Information section at the end of this article.

How to cite this article: Liu KY, Howard R, Banerjee S, et al. Dementia wellbeing and COVID-19: Review and expert consensus on current research and knowledge gaps. Int J Geriatr Psychiatry. 2021;1-43. https://doi.org/10.1002/ gps.5567 